\title{
Bringing Porous Organic and Carbon-Based Materials toward Thin-Film Applications
}

\author{
Stefan Wuttke,* Dana D. Medina, Julian M. Rotter, Salma Begum, Timothée Stassin, Rob Ameloot, Martin Oschatz, \\ and Manuel Tsotsalas*
}

Porous materials have attracted tremendous scientific and industrial interest due to their broad commercial applicability. However, some applications require that these materials are deposited on surfaces to create thin films. Here, the recent progress of new porous thin-film material classes is described: porous organic molecular materials, porous organic polymers, covalent organic frameworks, and nanoporous carbon. In each case, the state of the art and current barriers in their thin-film fabrication, as well as intrinsic material advantages that are suited for different applications are presented. By highlighting the unique structural characteristics and properties of these materials, it is hoped that increased research development and industrial interest will be fostered, which will lead to new methods of thin-film synthesis and consequently to new applications.

\section{Introduction-The "Renaissance" of Porous Materials}

To call the recent burst of interest in porous materials a "Renaissance" may be dramatic - porous materials are ubiquitous in nature and have been used by mankind since the height of the Egyptian Empire. However, it is obvious that their scientific and economic potential has drastically increased over the last few decades. Today, porous materials are used in many different kinds of technology.

Generally speaking, porous materials are solids with cavities or channels that are deeper than they are wide. According to the International Union of Pure and Applied Chemistry, porous materials can be divided into three categories: microporous, mesoporous, and macroporous. Materials whose pore widths exceed $50 \mathrm{~nm}$ are macroporous, widths between 2 and $50 \mathrm{~nm}$ are mesoporous, widths smaller than $2 \mathrm{~nm}$ are microporous. ${ }^{[1]}$
Alternatively, porous materials can be divided into three material classes: organic, inorganic, and hybrid materials.

A very common porous material is activated carbon, whose high adsorption capacities make it an ideal adsorbent for a variety of gases and molecules.. ${ }^{[2]}$ Zeolites are perhaps the most important class of inorganic porous materials, consisting mainly of aluminum, silicon, and oxygen. These are used as catalysts in the petrochemical industry, specifically as ion exchangers in detergent production, or as molecular sieves. Unfortunately, the applications of zeolites are limited by the small range of pore sizes zeolites can support $(0.5-1 \mathrm{~nm}) \cdot{ }^{[3]}$

These limitations spurred the development of new porous compounds with tuneable and larger pore sizes: mesoporous materials. The first compounds were only crystalline in terms of pore structure; the walls between the pores consisted of amorphous silicon dioxide or other metal oxides. One striking example of this is porous silica materials, which are usually synthesized using a bottom-up approach, in which small organic molecules or surfactants act as a template for the porous structure of the silica framework. ${ }^{[4,5]}$ These materials are characterized by large pore volume, large surface area, and chemical functionability. ${ }^{[6]}$

Although these purely inorganic materials are useful in their own right, an exponential number of hybrid structures can also be made, opening up an entirely new class of materials. Reticular chemistry to create ordered arrays of organic and inorganic building units into extended hybrid frameworks, so called metal-organic frameworks (MOFs). ${ }^{[7,8]}$ The unprecedented
Dr. S. Wuttke

School of Chemistry

Joseph Banks Laboratories

University of Lincoln

Lincoln LN6 7TS, UK

Dr. S. Wuttke, Dr. D. D. Medina, J. M. Rotter

Chemistry Department and Center for NanoScience

Ludwig-Maximilians-Universität München (LMU)

80539 Munich, Germany

E-mail: stefan.wuttke@cup.uni-muenchen.de

\author{
Dr. S. Begum, Dr. M. Tsotsalas \\ Institute of Functional Interfaces (IFG) \\ Karlsruhe Institute of Technology (KIT) \\ 76344 Eggenstein-Leopoldshafen, Germany \\ E-mail: manuel.tsotsalas@kit.edu \\ T. Stassin, Prof. R. Ameloot \\ Centre for Surface Chemistry and Catalysis \\ KU Leuven \\ 3001 Leuven, Belgium \\ Dr. M. Oschatz \\ Department of Colloid Chemistry \\ Max Planck Institute of Colloids and Interfaces \\ 14476 Potsdam, Germany
}


surface area and structural chemical tuneabilty make MOFs useful in many applications. ${ }^{[7,10-18]}$ So far, more than 60000 different structures have been reported in the Cambridge Structural Database (CSD). ${ }^{[19]}$

Industrial applications of porous materials often require them to be produced as thin films, and therefore thin-film science has driven the development of new technology perhaps more than any other field. Thin films are already crucial elements in energy generation and storage, electronics, optical coatings, hard coatings, magnetic films, corrosion resistance, membranes, light-emitting diodes (LEDs) and chemical sensors. ${ }^{[20]}$ Tremendous advances in thin-film deposition techniques were necessary to launch the modern area of film technology, ${ }^{[21]}$ and further advancement requires broadening our understanding of novel porous material classes that can be processed into thin films.

On contrary emerging class of processable microporous materials, polymers of intrinsic microporosity (PIMs) based membranes show interesting properties in transport of ions and separation of gases. ${ }^{[22]}$ In commercial realm, in $20153 \mathrm{M}$ launched PIM-1 based colorimetric sensor that is used as an end-of-service-life-indicator for organic vapor respirator cartridges. ${ }^{[23]}$ By virtue of microporous polymer networks high surface areas and microporous characteristics, they show great application potential in challenging energy and environmental issues mostly characterized for gas storage and separation, ${ }^{[24]}$ heterogeneous catalysis, ${ }^{[25]}$ and photoluminescence-based sensing. ${ }^{[26]}$ The conjugated nature and semiconducting properties of conjugated microporous polymers (CMPs) makes them interesting for strong photoluminescence, optical sensing of molecules or metal ions entering the porous framework, organic electronic applications, e.g., organic LEDs, solar cells or field effect transistors. ${ }^{[27-32]}$ CMPs for photocatalytic applications has also risen tremendously. ${ }^{[33]}$ Specific application of microporous materials, i.e., porous organic molecular materials (POMMs), porous organic polymers (POPs), covalent organic frameworks (COFs), and nanoporous carbon materials are briefly described in respective sections of this review. As potential application of microporous materials is not extensively covered in our review rather processing of microporous materials into film is the main focus of this review, interested readers are guided to excellent reviews on the synthesis and applications of these porous organic polymers have published recently. ${ }^{[34-45]}$

The goal of this article is to give an overview of the next generation of porous organic and carbon-based thin-film materials. This paper will be limited to the newest porous material classes, namely POMMs, POPs, COFs, and nanoporous carbon materials. In Table 1 we provide a summary of the discussed microporous material classes and compare key properties. We wish to provide a snapshot of what is currently known about their chemistry, thin-film fabrication, and applications. After discussing the basic chemistry and properties underlying these material classes, our article will provide an understanding of the principles and challenges of their thin-film synthesis, which is crucial for their successful integration into sophisticated devices. We want to give readers insight into the performance of different thin films and inspire them with the scientific and technological potential we see in them.

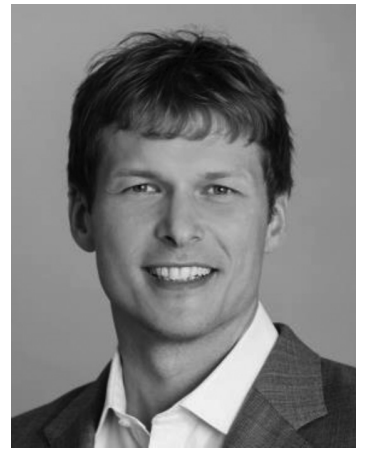

Stefan Wuttke has been leader of the research group "Wuttkegroup for Science," hosted at the Institute of Physical Chemistry at the University of Munich (LMU), and at the Center for Nanoscience (CeNS) at the LMU (Germany), since 2011. Currently, he is a Senior Lecturer in the Chemistry School at the University of Lincoln (UK). His principal focus is the design, synthesis, and functionalization of MOFs and their nanometric counter parts to target biomedical applications. At the same time, he intends to establish the basic understanding of the chemical and physical elementary processes involved in the synthesis, functionalization, and application of these hybrid materials.

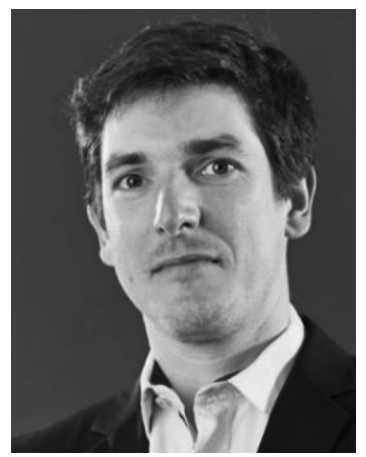

Manuel Tsotsalas studied chemistry and obtained his Ph.D. at the University of Münster. After a postdoctoral stay at Kyoto University, he joined the Karlsruhe Institute of Technology (KIT) in 2013, where he is currently leading a Helmholtz young investigator group, hosted at the Institute of Functional Interfaces and the Institute of Organic Chemistry and is PI in the SFB 1176 "molecularly structuring of soft matter." His research interests focus on the interfacial synthesis and hierarchical structuring of porous polymers to apply them as novel nanomembranes and bioactive surface coatings.

\section{Porous Organic Molecular Materials Thin Films}

Strategies to form Permanently Microporous Materials Based on Discrete Organic Molecules: Central to the discussion of microporous molecular materials is the question of how the molecular structure and connectivity of the building blocks create porosity. Porous network solids, whether crystalline zeolites, ${ }^{[46]}$ MOFs, ${ }^{[7]}$ COFs (see Section 4), or amorphous carbon materials (see Section 5), are characterized by extended directional coordination or covalent bonding (Figure 1A). Conversely, in porous molecular solids covalent bonding is limited to the molecular building block level. This section focuses on those materials built up from discrete organic molecular units held together through weak interactions (Figure 1B). Thus, examples where these units are used as ligands in network solids, ${ }^{[47]}$ or as filler in polymeric matrixes ${ }^{[48]}$ are not discussed.

Different strategies have been followed to create microporosity in organic molecular materials: 
Table 1. Summary and comparative key points of microporous material classes.

\begin{tabular}{|c|c|c|c|c|}
\hline & POMM-(NMCs,OMIMs, POCs) & POPs (PIMs, HCPs, CMP, PAF) & COF & Microporous activated carbon \\
\hline Design & Assembly of discrete molecular solids & $\begin{array}{l}\text { 3D network structures, PIMs contorted } \\
\text { polymer chains }\end{array}$ & $2 \mathrm{D}$ or $3 \mathrm{D}$ structures & $\begin{array}{c}\text { OD,1D or 2D Random disorder } \\
\text { structure }\end{array}$ \\
\hline Crystallinity & $\begin{array}{l}\text { NMCs Crystalline OMIMs amorphous } \\
\text { POCs crystalline or amorphous }\end{array}$ & $\begin{array}{c}\text { Amorphous, in PAF Small crystalline } \\
\text { domains }\end{array}$ & Modest to high & amorphous \\
\hline Porosity & $\begin{array}{l}\text { Microporous, internal microporosity } \\
\text { (cavity) and/or external microporosity } \\
\text { (ineffective packing) }\end{array}$ & Mostly microporous, broader pore sizes & $\begin{array}{l}\text { Microporous /mesopo- } \\
\text { rous narrow pore size } \\
\text { distribution }\end{array}$ & $\begin{array}{l}\text { Narrow pores, defects based } \\
\text { porosity }\end{array}$ \\
\hline Bonding/packing & $\begin{array}{l}\text { covalent (discrete unit), packing of discrete } \\
\text { units via weak intermolecular interaction } \\
\text { (HOF, hydrogen bonding, SOFs beside } \\
\text { hydrogen pi-pi interaction) }\end{array}$ & Covalent (irreversible reactions) & $\begin{array}{l}\text { Covalent (reversible } \\
\text { reactions). }\end{array}$ & Covalent, Pi-pi stacking \\
\hline Chemical reaction & Schiff base condensation, packing & $\begin{array}{l}\text { highly diverse, range from metal-catalyzed } \\
\text { couplings to metal-free condensation } \\
\text { reactions }\end{array}$ & $\begin{array}{l}\text { produced via condensa- } \\
\text { tion reactions }\end{array}$ & $\begin{array}{l}\text { Carbonization, condensation of } \\
\text { polynuclear aromatic units }\end{array}$ \\
\hline Solubility & Mostly soluble & $\begin{array}{l}\text { Mostly insoluble with exception of soluble } \\
\text { PIMs and one example of soluble CMP }\end{array}$ & Insoluble & Insoluble \\
\hline Thin-film deposition & $\begin{array}{l}\text { NMCs and OMIMs no report on thin film } \\
\text { deposition, POCs thin-films reported }\end{array}$ & $\begin{array}{l}\text { Examples of surface growth, a number of } \\
\text { reports on thin-film deposition }\end{array}$ & $\begin{array}{l}\text { examples of surface } \\
\text { growth }\end{array}$ & Well established \\
\hline
\end{tabular}

i) External porosity resulting from packing of the molecular units in the solid state. These assemblies can be ordered by directing supramolecular interactions, whether spontaneous or templated, resulting in crystal porosity (Figure 1C). Nanoporous molecular crystals (NMCs) are examples of such extrinsically porous crystalline materials. ${ }^{[49]}$ Alternatively, there are amorphous assemblies of rigid and bulky compounds packing inefficiently in the solid state where external porosity in the resulting disordered materials is a direct consequence of the molecular structure (Figure 1D). The terminology used in literature can be misleading as these molecules have often been referred to as Organic Materials of Intrinsic Microporosity. ${ }^{[50]}$

ii) Internal porosity inherent to the molecular structure. The shape-persistent cavities or clefts found in these compounds act as prefabricated pores, independently of the degree of ordering in the assembly (Figure 1E).

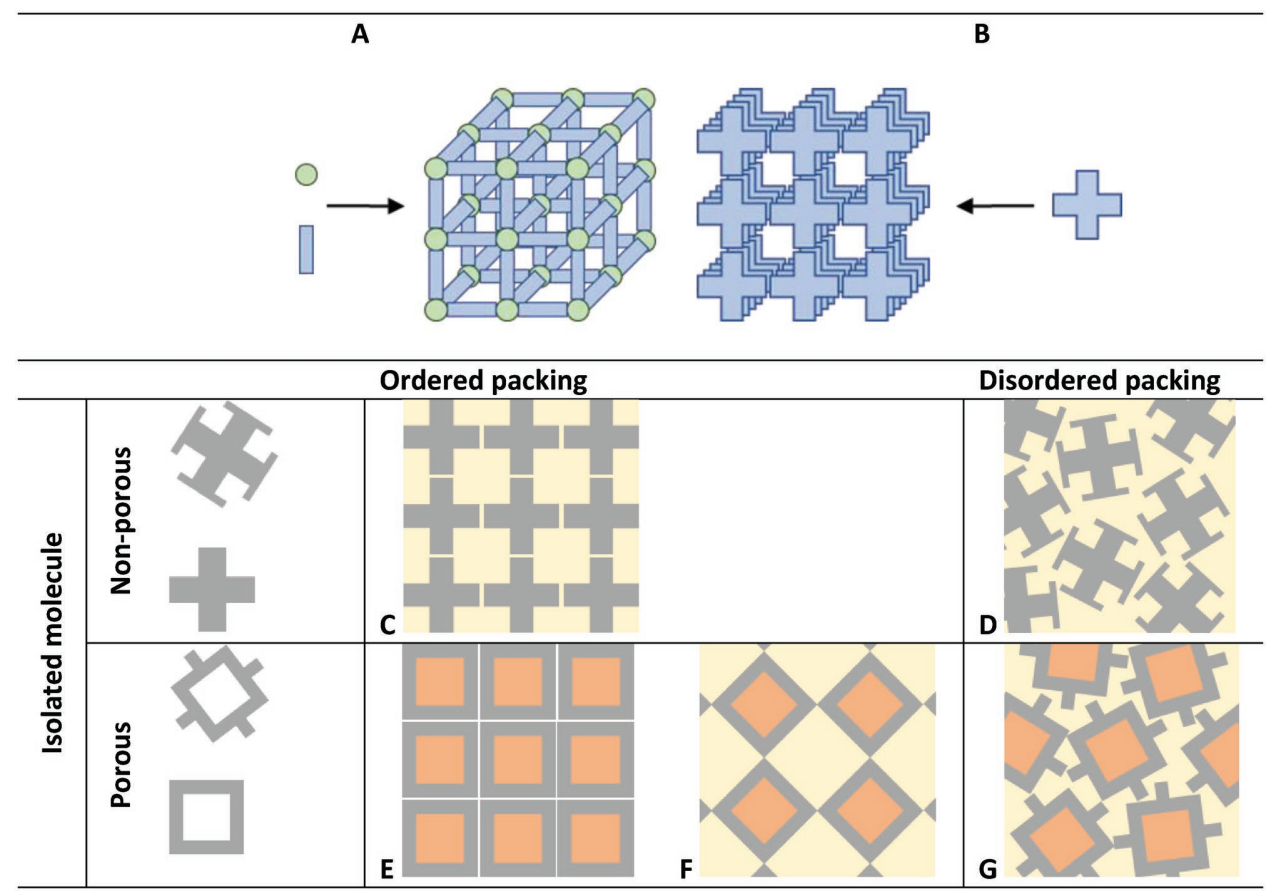

Figure 1. A) Porous network solid characterized by extended directional bonding and B) porous molecular solid resulting from the assembly of discrete units through weak intermolecular interactions. C-G) External (yellow) and/or internal (orange) porosity in molecular solids depending on the degree of ordering in the assemblies and the porosity of the molecular units in isolation. 
iii) Internal porosity supplemented by external porosity when cage compounds packing fashions generate additional void volume, which can be ordered (Figure $1 \mathrm{~F}$ ) or disordered (Figure 1G).

The distinguishing features of molecular solids compared to network solids (e.g., solubility), and the timeline of the various molecular building blocks in use have been extensively reviewed elsewhere. ${ }^{[51,52]}$ The following paragraphs give an overview of their chemistry and highlight key features that are essential to understand the potential and current challenges for their applications as thin films.

Inclusion Compounds and NMCs: In general, molecular solids tend to maximize attractive interactions and minimize empty space during crystallization. For at least $15 \%$ of molecular crystals reported in the CSD, crystal formation is paired with the incorporation of another molecule, giving rise to an inclusion compound. The guest molecules, usually the crystallization solvent, can be removed either by heating, vacuum, or in some cases, simple exposure to the atmosphere. However, solvent removal often results in the rearrangement or even destruction of the original crystalline order and loss of porosity. Nevertheless, a number of inclusion compounds retain the ordered packing of the host molecules and display permanent external porosity. The resulting structures have been named "nanoporous molecular crystals." ${ }^{[49]}$ It is important to note that the concept of crystal porosity is still lacking a clear terminology and researchers have been using the word "porous crystal" or claiming porosity in crystals in many different ways. However, reversible gas adsorption after complete removal of included molecules has been suggested as definite proof for porosity. ${ }^{[53]}$ Tris(o-phenylenedioxy)cyclotriphosphazene was the first molecular crystal unambiguously shown to be nanoporous $\left(2.7 \mathrm{mmol} \mathrm{CO}_{2} \mathrm{~g}^{-1}\right) \cdot{ }^{[54]}$

The design of stable porous crystalline assemblies based on weak noncovalent interactions remains a challenge, in particular for relatively complex organic molecular units. ${ }^{[55,56]}$ A central paradigm in crystal engineering is to synthesize building blocks with strong directional interactions, or capable to direct the assembly into a supramolecular structure. Hydrogen-bonding has been very popular in this respect. In the recent review by Han et al., these porous hydrogenbonded organic frameworks (HOFs) are divided in eight categories based on the nature of the hydrogen-bonded motifs. ${ }^{[57]}$ Brunauer-Emmett-Teller (BET) surface areas ( $\mathrm{SA}_{\mathrm{BET}}$ ) as high as $2796 \mathrm{~m}^{2} \mathrm{~g}^{-1}$ have been reported by Mastelerz and Oppel for crystals of triptycene trisbenzimidazolone (TTBI) grown by slow vapor diffusion of acetone into a saturated dimethyl sulfoxide solution (Figure 2-1). ${ }^{[58]}$ Owing to the unprecedented large cylindrical channels (1.45 $\mathrm{nm}$ in diameter) and to avoid any stress on the hydrogen bonding pattern, solvent exchange was preferred to direct thermal activation. Besides hydrogenbonding, $\pi-\pi$ interactions have been used in a series of the so-called Supramolecular Organic Frameworks (SOFs). ${ }^{[59]}$ Crystals of prototypical SOF-1, a system combining bulky polyaromatic groups, lateral nitrile and pyridyl functional groups conjoined by dihydropyridyl moieties to afford spatially oriented hydrogen bond donor and acceptor groups, grown from a hot $N, N$-dimethylformamide (DMF) solution covered with benzene and methanol layers, have a BET surface area of $474 \mathrm{~m}^{2} \mathrm{~g}^{-1}$ after thermal activation at $130{ }^{\circ} \mathrm{C}$. ${ }^{[59]}$ One more successful approach toward supramolecular assemblies is the sergeant-soldiers principle, wherein a small fraction of chiral molecules (sergeants) is used to skew the handedness of achiral molecules (soldiers) to generate a homochiral structure. ${ }^{[60]}$ Only a number of planar supramolecular assemblies have been grown as single 2D layers on surfaces and shown to allow guest adsorption. ${ }^{[61,62]}$ The question remains as from when these single layers, or stacks of these layers reminiscent of 2D COFs, can be classified as porous.

Although the authors could not find any report on the deposition as thin films of any of the abovementioned examples, it seems feasible to transpose the synthetic principles behind the solution-based growth of solvated crystals and subsequent evacuation from traditional organic synthesis vessels to surfaces. Moreover, crystal growth by sublimation, as reported by Thallapally et al. for pure 5,11,17,23-tetra-tert-butyl-25,26,27,28tetramethoxy-2,8,14,20-tetrathiacalix[4]arene at $240{ }^{\circ} \mathrm{C}$ under reduced pressure, offers perspectives for solvent-free deposition routes. Although nonporous, crystals of this substituted hydrophobic calixarene undergo a single-crystal-to-single-crystal phase transformation upon exposure to water, during which water molecules become embedded in the lattice voids.

Organic Molecules of Intrinsic Microporosity (OMIMs): Molecular engineering of porous amorphous solids involves the design and synthesis of bulky organic molecular building units capable of packing ineffectively in the amorphous phase. From a theoretical perspective, the most inefficient packing is produced for both $2 \mathrm{D}^{[63]}$ and $3 \mathrm{D}$ objects ${ }^{[64]}$ when the compounds shapes possess highly concave faces. Accordingly, large molecules with multiple concavities based on combinations of aromatic cores with bulky aromatic groups, similar to previously utilized precursors for PIMs ${ }^{[65]}$ were first modeled and then synthesized. By altering the size and bulk of the terminal groups, a number of compounds with BET surface areas larger than $300 \mathrm{~m}^{2} \mathrm{~g}^{-1}$ could be produced, and called Organic Molecules of Intrinsic Microporosity (Figure 2-2). ${ }^{[50]}$ It is to note that this terminology follows from another definition of intrinsic microporosity in the context of polymer chemistry, namely "a continuous network of interconnected intermolecular voids, which forms as a direct consequence of the shape and rigidity of the component macromolecules." Interestingly, the efficiency of the arm group structural unit in generating microporosity was observed to decrease in the order: propellane $>$ triptycene $>$ hexaphenylbenzene $>$ spirobifluorene $>$ naphthyl = phenyl. Additionally, the introduction of bulky hydrocarbon substituents on the arm groups significantly enhances microporosity by further reducing packing efficiency. Moreover, the introduction of methyl groups at internal position within the compound structure (e.g., bridgehead position of trypticene units) lowers the porosity as they occupy space, but unlike peripheral substituents they do not contribute to the generation of free volume by inefficient packing. ${ }^{[6]}$ The Mastalerz group also reported a $\pi$-extended triptycene compound similarly designed to pack inefficiently and achieving an apparent BET surface area $\left.5754 \mathrm{~m}^{2} \mathrm{~g}^{-1}\right)^{[67]}$ similar to the most porous OMIM-12 $\left(726 \mathrm{~m}^{2} \mathrm{~g}^{-1}\right)$ and even comparable to the prototypical PIM-1 $\left(850 \mathrm{~m}^{2} \mathrm{~g}^{-1}\right) \cdot{ }^{[65]}$ 


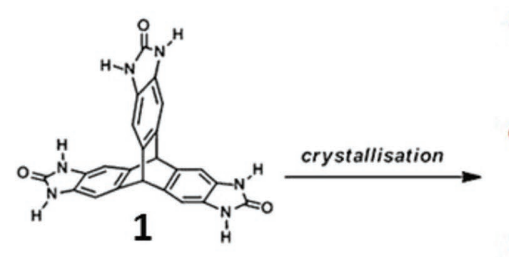

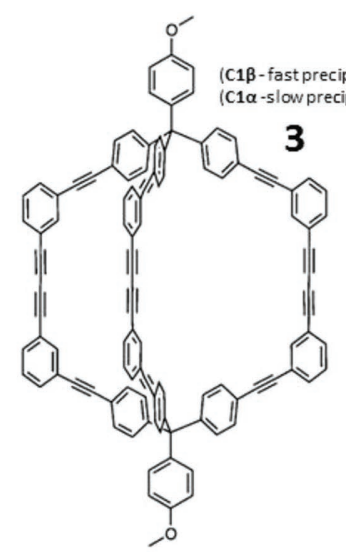

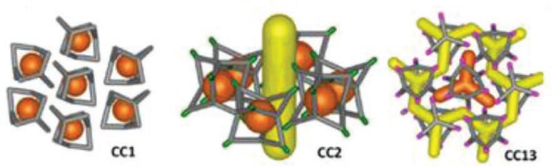

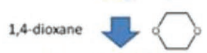
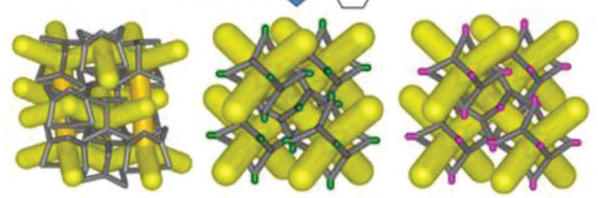

A

Window-to-window cage packing: 3D diamandoid pore structure
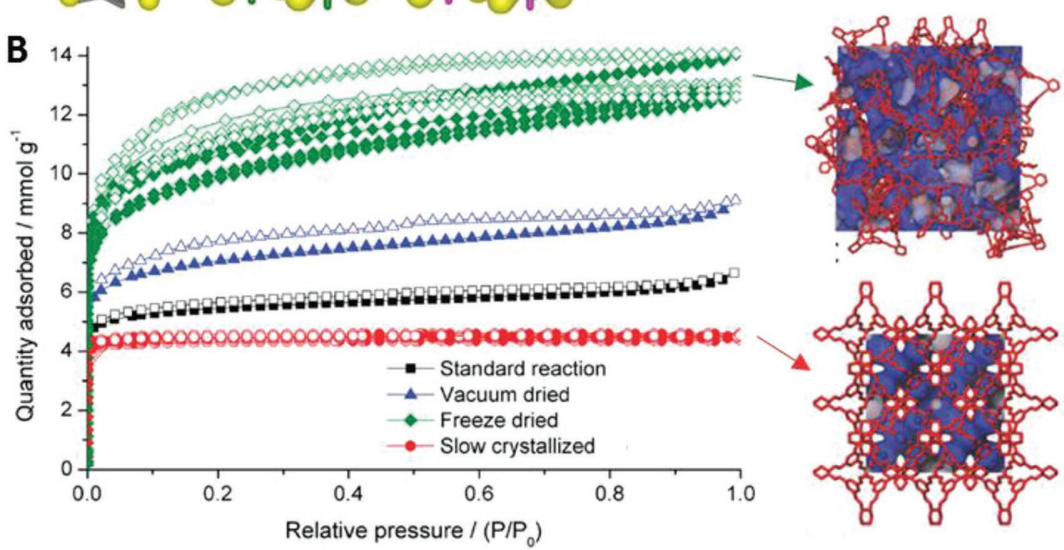

\section{Freeze-drying} Amorphous
$S A_{\text {EET }}=859 \mathrm{~m}^{2} \mathrm{~g}^{2}$

\section{5}

5

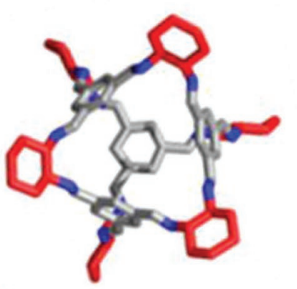

Figure 2. 1) Structure, crystal packing and BET surface area of triptycene trisbenzimidazolone (TTBI), 2) structure and BET surface area of OMIM-10-14, 3) structure of Doonan cage $\mathrm{Cl}$ and BET surface area of the two different crystalline polymorphs obtained by slow and fast precipitation, 4) structure and BET surface area of a triptycene-based cage, 5) structure of Cooper Cage CC3 (cyclohexyl vertices). A) Schematic low-energy crystal packings for CC1 (hydrogens on vertices; formally nonporous), CC2 (methyl vertices; 1D external pore channels), and CC13 (dimethyl vertices; 2D layered pore structure with formally disconnected voids). As such, small structural changes to the vertex groups lead to three quite different crystal packings and pore topologies for the $\alpha$ polymorphs shown here (orange = disconnected voids; yellow = interconnected pores). Crystallization in the presence of 1,4-dioxane causes pseudoisostructural window-to-window packing for all three cage modules, causing the materials to mimic the 3D diamondoid pore structure of CC3 shown in D. B) $\mathrm{N}_{2}$ sorption isotherms (77 K) for homochiral CC3 produced by freeze-drying (green diamonds, 6 repetitions), vacuum evaporation (blue triangles), standard reaction (black squares), and slow crystallization (red circles, 6 repetitions). C,D) Molecular simulation of amorphous packing (top) and crystalline structure (bottom) of CC3, with the Connolly surface probed by $\mathrm{N}_{2}$ molecules (kinetic diameter of $3.64 \AA$ ) shown in blue, and average BET surface area extracted from the isotherms shown in (B). 1) Reproduced with permission. ${ }^{[58]} \mathrm{Copyright} 2012$, Wiley-VCH. 2) Reproduced with permission. ${ }^{[66]}$ Copyright 2016, Wiley-VCH. Reproduced with permission. ${ }^{[70]}$ Copyright 2014, Wiley-VCH. 3) Reproduced with

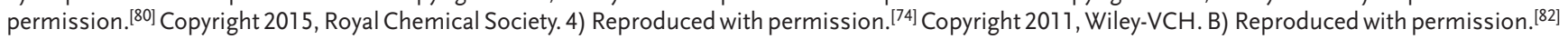
Copyright 2012, the American Chemical Society. 
Attempting to grow crystals from an OMIM were so far not successful and only amorphous phases were observed. The Mastalerz group succeeded recently in isolating four different polymorphs by slow evaporation of saturated solutions in adequate solvent. However, none remains crystalline upon exchange of the crystallization solvent, and only one shows specific surface areas as high as $350 \mathrm{~m}^{2} \mathrm{~g}^{1} \cdot{ }^{[67,68]}$ This value remains far less from the theoretically calculated extraordinary high specific surface areas $\left(>4000 \mathrm{~m}^{2} \mathrm{~g}^{-1}\right)$ for the solvated crystals, reminiscent of the difficulties to achieve permanent microporosity in NMCs. As for NMCs, there is surprisingly no report of OMIMs deposited as thin films.

Porous Organic Cages (POCs): In the solid state, shapepersistent cage compounds form crystalline or amorphous phases with various pore connectivities, where the internal microporosity of the molecular cavity can be supplemented by external microporosity when the cages are not packing tightly. The combination of large internal cavities and a certain design freedom to direct or frustrate packing in solid-state through solution-processing and cage side-group modifications, resulting in very high surface areas (up to $3758 \mathrm{~m}^{2} \mathrm{~g}^{-1}$ ), has attracted much attention to this field over the last 5 years. ${ }^{[69,70]}$

Prominent porous organic cages can be grouped based on the precursor and chemistry used for their synthesis. POCs reported by Cooper and co-workers are readily synthesized in high yields at the gram scale through a one-step Schiff base condensation of trialdehydes (typically benzene-1,3,5-tricarbaldehyde) with diamines (e.g., ethylene diamine) (Figure 2-5). ${ }^{[71-73]}$ Also based on imine linkages, Mastalerz and co-workers synthesized a series of cages by reacting triptycene triamine with various salicyldialdehydes derivatives, resulting in endo-functionalized cage compounds in moderate yields (Figure 2-4). ${ }^{[74,75]}$ The stability of imine-based cages can further be improved by post-synthetic modifications, ${ }^{[76]}$ or by using a slightly different precursor. ${ }^{[77]}$ Otherwise, robust carbon-carbon bonds have been used to construct entire cages by the Doonan group in a multistep reaction scheme at the milligram scale (Figure 2-3), ${ }^{[78]}$ but with new synthetic routes under investigation. ${ }^{[7-81]}$

The precipitation rate is a critical factor in determining the properties of the final solid. Access to different crystalline polymorphs of Doonan cage C1 was observed to be a kinetically driven process: rapid precipitation (seconds) yields a material with a BET surface area of $1153 \mathrm{~m}^{2} \mathrm{~g}^{-1}$ while slow evaporation (hours to days) yields a nonporous material, and the use of a rotary evaporator (minutes) gives a mixture of both. ${ }^{[78]}$ Similarly, by isolating Cooper cage CC3 from solution by a variety of routes with increasing precipitation rate, a direct correlation could be observed with BET surface areas, and an inverse relationship with the degree of crystallinity in the resulting materials (Figure $2 \mathrm{~B}, \mathrm{C}$ ). ${ }^{[82]}$ Next to rapid precipitation as an effective way to get amorphous materials, another strategy consists of "scrambling" cages (i.e., from direct co-reaction of two different amines during synthesis) to create a mixture of structures with a distribution of shapes (ASPOCs) that frustrates crystallization. ${ }^{83]}$ Whether amorphous cages have either higher ${ }^{[82]}$ or lower porosity ${ }^{[5]}$ than their respective crystalline forms will eventually depend on the pore connectivity and the density of the crystalline phase, and also how closely the cages can pack in the amorphous state.
Solvents can also act as structure-directing agents. For example, 1,4-dioxane vapor directs the crystal packing for all three $\mathrm{CC} 1, \mathrm{CC} 2$, and $\mathrm{CC} 3$ cages from the lowest-energy polymorph to a structure with $3 \mathrm{D}$ channels formed by a window-to-window packing (Figure 2A). ${ }^{[84]}$ Later, this concept was extended to the homochiral CC3-R and CC4-R. By identifying directing solvents that either reinforce or disrupt the solid-state window-to-window packing arrangement, changes in the crystal packing modes were triggered, thus achieving guestmediated control over solid-state porosity. ${ }^{[85]}$

Considering cages as soluble, molecular pores, modular "mix-and-match" strategies have been developed. Taking advantage of the favorable interaction between cages of opposite chirality and a markedly lower solubility for the cage racemate, it was made possible to produce porous (co-)crystals by mixing enantiomers in solution. ${ }^{[82,86]}$ Later, this design strategy was extended to ternary cage co-crystals with three molecular components and to cages of different geometries. By varying the molecular composition in solution, thus the eventual composition of these porous organic alloys, it is possible to fine-tune surface and sorption properties, whereas size and morphology control can be achieved by varying the mixing rate and mixing temperature. ${ }^{[87,88]}$

Examples of POC Thin-Film Depositions and Applications: Several applications of POCs thin films have been reported in literature, including selective membrane top layers for gas separations, sensing based on optics or absorption spectroscopy, templates for nanostructured films, supports for catalysts, ${ }^{[89]}$ as well as gravimetric sensing with Quartz Crystal Microbalances (QCMs) ${ }^{\left[{ }^{[0,91]}\right.}$ Cage thin films might be used as building blocks for functional materials and devices, such as molecular sensors. The flexible property of cage solids and thin films may be useful in other applications, for example, controlled release of guests (e.g., drug molecules), or adaptive materials. ${ }^{[89]}$ Also, the enhanced electron and proton conductivities through guest inclusions measured in POCs offers opportunities for integrated thin-film applications. ${ }^{[2,93]}$ While the key feature of solution-processability has been highlighted in many of the abovementioned studies on porous molecular crystals, OMIMs and POCs, it is surprising that this property has not yet been fully exploited. To date, three key reports on thin-film depositions of porous organic molecular materials have been published, all making use of POCs.

In 2012, Brutschy et al. exploited for the first time the solubility of porous shape-persistent cage compounds to "process porosity" into thin films. ${ }^{[90]}$ Coatings of 10-30 molecular layers (10 ng) of seven derivatives of their previously reported adamantanoid triptycene-based salicylbisimine cage compound (Figure 2-4) were deposited on QCMs by electrospraying. ${ }^{[8,94]}$ The coatings were assumed amorphous based on the deposition conditions. The microporosity of the coatings was demonstrated by the gravimetric uptake and release of aromatic guests.

Song et al. published an extensive study on the deposition of POCs thin films by spin-coating solutions of five different Cooper cages in volatile solvents (dichloromethane (DCM), chloroform). ${ }^{[89]}$ Transparent and pinhole-free films were obtained on glass or silicon substrates (Figure 3B). The nature of the solvent influences the evaporation rate and defines the compound 

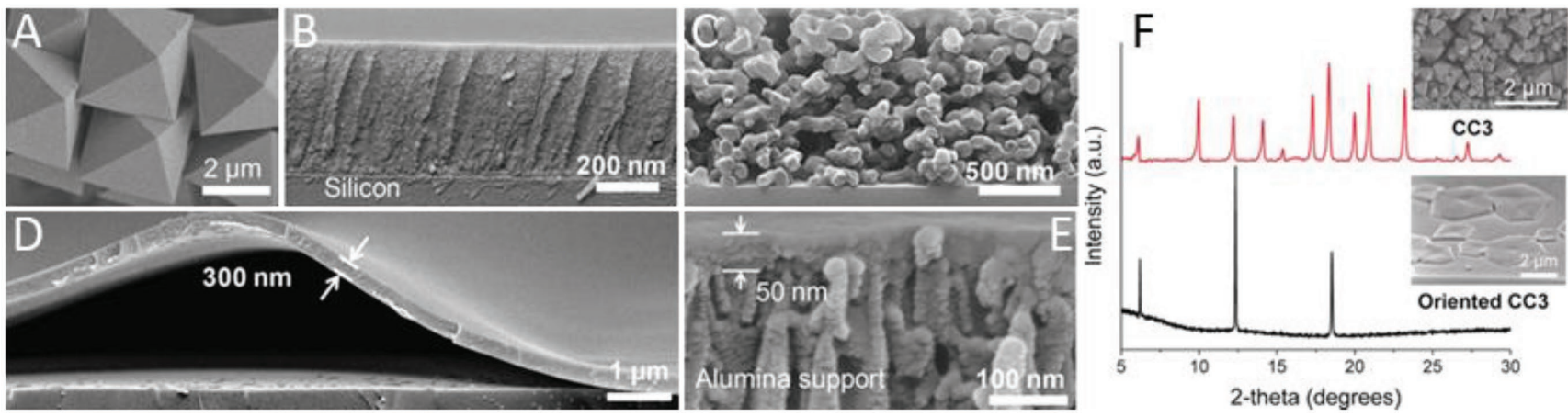

Figure 3. SEM images of A) CC3 crystals, B) CC3 thin film, spin-coated from CC3:MeOH:DCM = 4:2:98 (w:w:w), C) CC3 thin film, spin-coated from $C C 3: \mathrm{MeOH}: D C M=4: 15: 85$ (w:w:w), D) buckling of ASPOC thin films occasionally occurred upon exposure to fracture in liquid nitrogen, E) crosssectional SEM of $50 \mathrm{~nm}$ thick CC3 thin film coated on $\mathrm{Al}_{2} \mathrm{O}_{3}$ support, $\mathrm{F}$ ) XRD patterns and SEM images of bulk 3D CC3 crystals (top) and oriented 2D CC3 crystals grown on a silicon wafer (bottom). (A-E) Reproduced with permission. ${ }^{[89]}$ Copyright 2016, the Authors, published by Wiley-VCH. (F) Reproduced with permission. ${ }^{[96]}$ Copyright 2005, the Royal Society of Chemistry.

solubility, thus achievable compound concentration and film thickness. For example, by varying the concentration of ASPOC molecules in chloroform from 1 to $5 \mathrm{wt} \%$, the thickness of the spin-cast film was changed from $100 \mathrm{~nm}$ to nearly a micrometer. Co-solvents were used to enhance solubility, but too large amounts induced phase separation by solvent evaporation. For example, small amounts of methanol (MeOH) (2-10\%) in DCM enhanced the solubility of CC3 and led to densely packed microporous films, but excess $\mathrm{MeOH}(>10 \%)$ generated hierarchically porous films with interconnected nanocrystals (Figure 3C). These nanocrystals could be observed as weak peaks on the X-ray diffraction (XRD) pattern while all other films were amorphous. Some degree of mechanical flexibility was deduced from the observation by scanning electron microscopy (SEM) of occasional film buckling and exfoliation, most likely due to stress upon fracture in liquid nitrogen (Figure 3D). To target gas separation applications, cage thin films were spincoated on porous anodized aluminum oxide discs, resulting in composite membranes with molecular sieving properties. So, a $50 \mathrm{~nm}$ CC3 thin-film membrane achieved a $\mathrm{CO}_{2} / \mathrm{N}_{2}$ selectivity of 18.7 with a $\mathrm{CO}_{2}$ permeance of $91.7 \times 10^{-8} \mathrm{~mol} \mathrm{~m}^{-2} \mathrm{~s}^{-1} \mathrm{~Pa}^{-1}$ (Figure 3E).

Recently, the challenge of depositing crystalline films was successfully overcome by Cooper and co-workers who grew oriented cage crystals on silicon wafers and glass substrates. ${ }^{\text {[95] }}$ Starting again from solutions of CC3 in dichloromethane or chloroform, but using the simple technique of dip coating, multiple $1.41 \mathrm{~nm}$ thick oriented cage layers could be deposited, resulting in hexagonal-shaped 2D crystals with an average thickness of $200 \mathrm{~nm}$ and a diameter between 3 and $5 \mu \mathrm{m}$ (Figure $3 \mathrm{~F}$ ). Using a multiple dip-coating process to promote secondary growth, a better substrate surface coverage (up to $85 \%$ ) could be achieved but going paired with a loss of orientation in the uppermost cage layers. In addition, atomic force microscopy allowed to observe local point defects in cage crystals for the first time. The defects concentration was also found to be correlated with the crystallization rate through the substrate pulling speed.

Of the three above-mentioned cage film deposition methods, spin-coating is particularly attractive for its great capability to produce uniform films over large area with a highly controllable and reproducible film thickness, and its widespread use in industry. ${ }^{[96]}$ However, the preferential orientation and tunable defects concentration of films deposited by dip coating are beneficial for integrated applications in electronic devices and as electrodes for fuel cells. ${ }^{[97]}$

When considering solution-based thin-film deposition routes for organic molecular materials in general, adequate choice of the deposition solvent is critical with respect to activation. Indeed, evacuation of the as-deposited films can preferentially occur by vacuum or thermal treatment. Solvent-exchange of high-boiling point solvents, or solvents strongly interacting with the cages (e.g., hydrogen bonding) for less polar, more volatile solvents, is less straightforward for thin films than powders. ${ }^{[70]}$ Vapor-phase processes are also preferential to liquid-phase processes to prevent film disruption resulting from cage redissolution, although one could think of treatments to reduce the cage solubility and/or enhance the film mechanical properties after deposition. A number of vapor-assisted treatments have already reported on POCs such as solid-state phase transformations ${ }^{[98]}$ or loading with active compounds, ${ }^{[92]}$ but other processes aiming at cages chemical modification or cross-linking seem reasonable to achieve.

\section{Porous Organic Polymer Thin Films}

POPs are build up from molecular building blocks that are connected via irreversible chemical reactions under kinetic control, leading to typically amorphous but highly robust materials. ${ }^{[99]}$ POP structures range from highly cross-linked networks to linear contorted polymers and have been denoted as PIMs, highly cross-linked polymers (HCPs) CMPs, and porous aromatic frameworks (PAFs). POP as a more general term broadly represent these different classes of microporous materials. Figure 4 depicts typical building blocks and polymer structures of POPs.

Typical reactions for the synthesis of POPs include metalmediated cross-coupling reactions (e.g., Buchwald-Hartwig, Eglinton, Heck, Sonogashira, Suzuki and Yamamoto) and other popular reactions are click-type reactions, acid or base-catalyzed polycondensation reactions, trimerizations or oxidative reactions and Friedel-Crafts type couplings. Despite the lack of long 


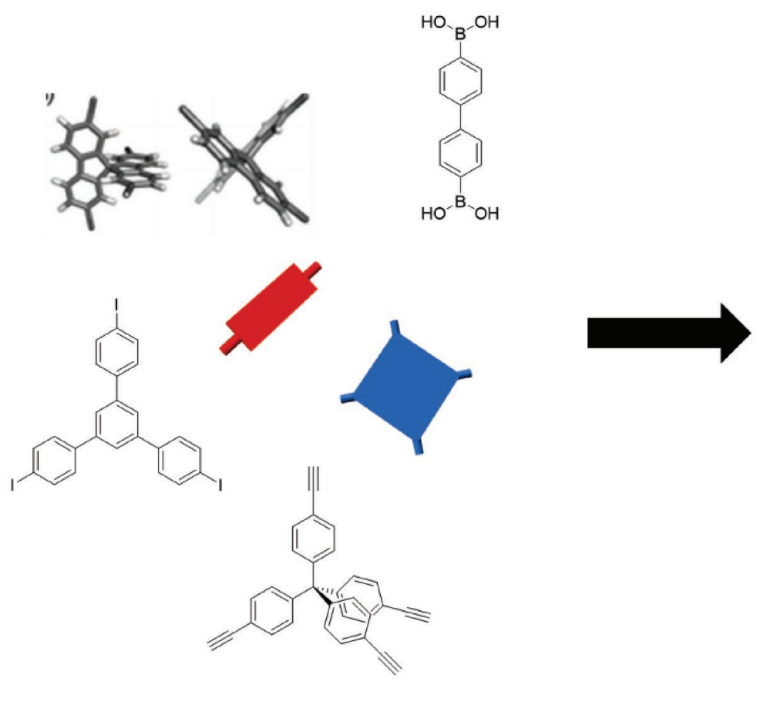

Figure 4. Examples of POP building blocks and polymer structures.

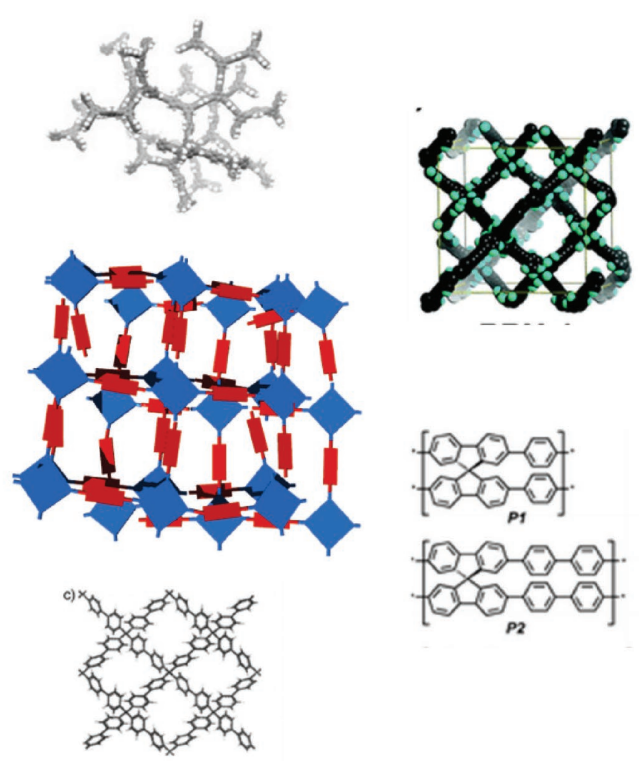

range order, POPs have been synthesized possessing tremendous porosity with tuneable pore size distributions. ${ }^{[100,101]}$ The BET surface areas $\left(5640\right.$ and $6461 \mathrm{~m}^{2} \mathrm{~g}^{-1}$ ) for POPs are among the highest reported for porous materials to date. ${ }^{[22,102-104]}$

Compared to other microporous materials such as MOFs and COFs, the higher chemical and thermal stabilities that POPs possess have been claimed as major advantages, while still maintaining the possibility of including functional moieties and $\pi$-conjugated backbones. ${ }^{[105]}$ The robust nature of POPs, which can be combined with their large porosity makes them particularly appealing for highly demanding applications in rough conditions such as catalysis or gas separation. Highly cross-linked POPs also possess large morphological stability, which is important in composite devices where an intermixing of the different domains is undesirable for the devices performance.

To explore and utilize the high functionality and robust nature of the POPs, for many applications it is essential to deposit these frameworks onto solid surfaces, such as electrodes or semiconductors. In this section we will describe both the synthetic and processing techniques developed for different kinds of POPs, aiding their generation as thin films on conducting, transparent or even sacrificial substrates in order to generate homogeneous thin films and freestanding nanomembranes. An important aspect is the development of methods for localized depositions (patterning) and hierarchical structuring of these thin films.

POP Materials: POPs can be classified with regards to their ability to be processed in solution (linear structure) or whether they are intrinsically non soluble (network structure). ${ }^{[105]}$ Soluble POPs are usually processed into thin films using doctor blade or spin casting techniques. The first soluble rigid ladder-type POP reported by Budd and McKeown used the concept of rigid, contorted tectons to avoid dense packing of polymer chains, they are known as PIMs with pores dimensions in the range 0.4-0.8 nm. ${ }^{65,106,107]}$ Typically, PIMs are prepared by a doublearomatic nucleophilic substitution of tetraphenol monomers having contorted centers with tetrahalogenated monomers to form a ladder-type chain structures via formation of a dibenzodioxin linkage. Several approaches are developed for structurally modified new PIMs with improved mechanical stability including post-modifying PIMs, ${ }^{[108-110]}$ cross-linking PIMs (3) and copolymerizing PIMs. ${ }^{[111]}$ PIMs exhibit that a network structure is not a pre-requisite for having microporosity within an organic material, however, it had been as well recognized that high surface areas and enhanced structural stability can be reached when a higher degree of crosslinking is attained. In order to process the insoluble highly cross-linked network structures, techniques need to be developed which enable the direct synthesis on the desired substrate, since the material cannot be processed into films once prepared as a bulk material. The different techniques developed for linear and network POPs to prepare porous polymer thin films are summarized in Figure 5.

The different techniques developed to prepare porous polymer thin films will be discussed in regard to (a) the homogeneity and roughness of the produced thin films, (b) the possibility to control the thickness and (c) the possibility to include multiple layers with precise control over their position in the film. Technical aspects include the need of surface modification prior to the synthesis and the generalizability of the method for different coupling reactions used in the synthesis of POPs and the tolerance of the different methods toward various functional groups within the molecular building blocks. In addition, we will discuss aspects such as synthesis speed, upscaling/possibility to coat large areas and robustness/reproducibility.

Porous Polymer Thin Films via Solution Processing Approach: Despite their rigid structures, several linear POPs, denoted as PIMs, are soluble in organic solvents. ${ }^{[106]}$ Processing techniques established for standard polymers are therefore also available for these materials, particularly spin coating or drop casting, leading to thin coatings and self-standing films of high surface area. ${ }^{[12]}$ PIM-based membranes show interesting properties in transport of ions and separation of gases. ${ }^{[105]}$ Gas separation 
Solution-processible Films

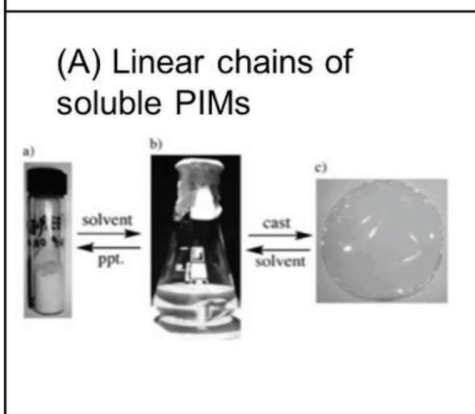

(C) Sol Gel approach

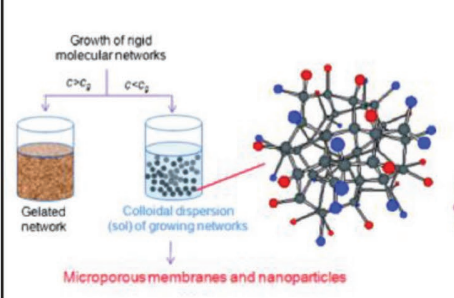

(B) Linear chains of soluble CMPs

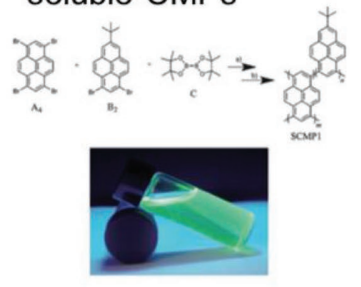

(D) Solution dispersible nanoparticles

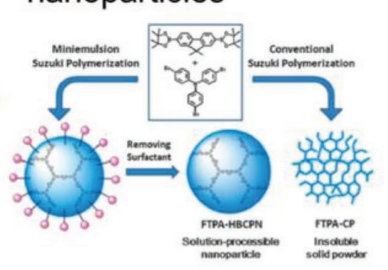

Film growth at solid interfaces
(E) Direct growth

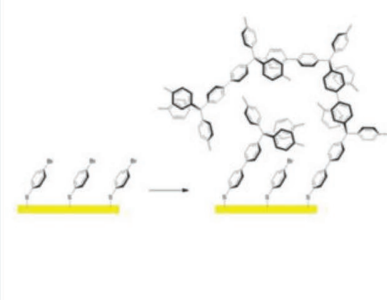

(G) Layer by layer growth

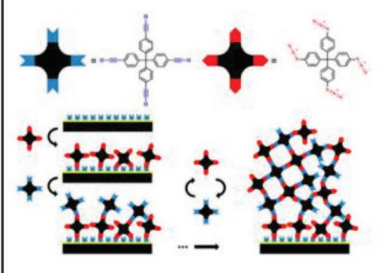

(F) Surface initiated polymerization

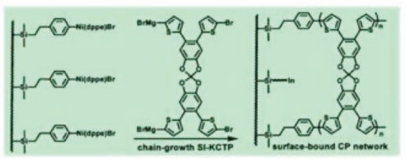

\section{(H) Electro polymerization}

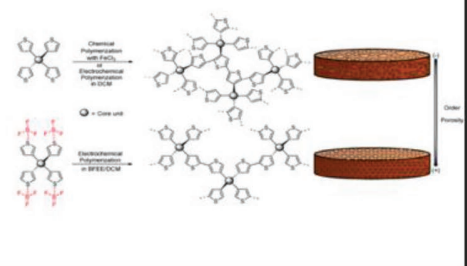

Figure 5. Thin-film deposition techniques for porous polymers of soluble (left) and insoluble (right) nature. A) PIM-1 in a) powder (a), b) THF, and c) as a solvent-cast film suitable for use as membranes. ${ }^{\left[{ }^{82]}\right.}$ B) Two-step one-pot synthesis of a soluble conjugated microporous polymer SCMP1; a solution of SCMP1 in THF shows green luminescence under UV irradiation ( $\lambda=254 \mathrm{~nm}$; image below the scheme) $\left.{ }^{[86]} \mathrm{C}\right)$ Amine/isocyanate polycondensation affords a sol of growing microporous molecular-network nanoparticles; for the particle model: $\mathrm{NCO}$ : red, $\mathrm{NH}_{2}$ : blue, tetrahedral cross-link point: grey). ${ }^{[88]}$ D) Preparation procedures for solution-processible FTPA-HBCPN and its insoluble analogue FTPA-CP. Reproduced with permission. ${ }^{[120]}$ Coypright 2013, the Royal Society of Chemistry. E) Schematic description of PAF-1 grown over a pre-functionalized gold substrate. Reproduced with permission. ${ }^{[113]}$ Copyright 2016, the Royal Society of Chemistry. F) Preparation of network polymer by Ni-catalyzed surface-initiated Kumada catalysttransfer polycondensation of thiophene-based monomers. Reproduced with permission. ${ }^{[123]}$ Copyright 2012, the American Chemical Society. G) Molecular building blocks of the POP network system and schematic representation of their layer-by-layer synthesis on functionalized surfaces. Reproduced with permission. ${ }^{[124]}$ Copyright 2014, the American Chemical Society. H) Thiophene-based monomers processed by electrochemical polymerization into microporous polymer networks.

properties of such membranes can be modulated in situ by introducing light responsive PIMs. ${ }^{[13]}$ However, aging was identified as a particular challenge in PIMs as the membrane performance cannot be sustained in long-term experiments.

Linear POPs possessing a conjugated backbone are in general poorly soluble. Cooper and co-workers reported the first example of a soluble POP possessing a conjugated backbone, denoted as soluble conjugated microporous polymer (SCMP), based on pyrene monomers and a two-step $\left(\mathrm{A}_{4}+\mathrm{B}_{2}\right)$-type Suzuki-catalyzed aryl-aryl coupling copolymerization. ${ }^{[114]}$ The soluble character in these POPs was introduced by incorporating solubilizing alkyl groups, following the strategy developed for preparation of discrete and soluble hyperbranched polyphenylene chains rather than extended network. Such soluble conjugated POPs can be processed from solution to form films, while the resultant porosity is a function of the processing conditions. (i.e., casted films are poorly porous in comparison to precipitated bulk powder). ${ }^{[115]}$

Ji-Woong Park and co-workers reported a so-called organic solgel synthesis for POP networks. ${ }^{[16]}$ The networks are synthesized by a two-stage mechanism, first forming a colloidal dispersion, which can still be solution processed, followed by the growth of the interconnected networks by solvent evaporation, analogous to the sol-gel synthesis of inorganic oxide networks. The resultant optically transparent films could be prepared with thicknesses of a few hundred nanometers to a few hundred micrometers, and those thicker than several micrometers could be removed from the substrate to yield free-standing films. Dai and co-workers have developed a technique similar to a sol-gel processes by pouring a solution of 4,4'-biphenyldicarbonitrile in the super acid $\mathrm{CF}_{3} \mathrm{SO}_{3} \mathrm{H}$ onto a flat dish. ${ }^{[117]}$ While the polymerization takes place, the solvent evaporates yielding a triazine-framework-based transparent and flexible film, which can afterward be pulled off to serve as a membrane for $\mathrm{CO}_{2}$ separation. The super acid serves as a catalyst allowing the trimerization reaction to take place at much lower temperatures than the originally applied conditions in $\mathrm{ZnCl}_{2}$ molten salt developed by Kuhn et al. ${ }^{[118]}$

Suobo Zhang and co-workers demonstrated a similar approach to overcome the issue of insolubility of POP networks once synthesized by preparing microporous polymeric films through in situ deprotection and polymerization of monomers on a flat glass dish. ${ }^{[119]}$ The sol-gel approach allows fast and efficient synthesis of porous polymer thin films on different substrates. However, the conditions for the polymerization 
need to be carefully optimized to guarantee a large degree of cross-linking and high porosity. From the aspect of film thickness the membranes were usually in the range of several micrometers, not permitting membranes in the nanometer range, which is another limitation of the sol-gel approach.

Another rather straightforward approach was applied by Wang and co-workers ${ }^{[120]}$ and Scherf and co-workers ${ }^{[121]}$ by preparing stable suspensions of POP nanoparticles. Both Sonogashira and Suzuki coupling polymerization were employed in the POP nanoparticles synthesis by in an oil-in-water emulsion, followed by posttreatment to remove surfactants. The nanoparticle suspensions can then be spin-coated to prepare homogeneous transparent thin films. The solution dispersible approach is an interesting method to coat surfaces with POPs, however not leading to continuous films and therefore not permitting membrane applications.

Growth of Porous Polymer Thin Films at Solid Interfaces: Porous Polymer Thin Films via Interfacial Growth: A straight forward approach for the synthesis of porous polymer networks on substrates was developed by the group of Thomas and co-workers by immersion of a substrate into the growth solution. ${ }^{[122]}$ In order to covalently attach the POP to a gold surface it was functionalized with a 4-bromothiophenol self-assembled monolayer, which acts as comonomer in the polymerization. The polymer films prepared by the direct growth method showed to be homogeneous and smooth, with few larger particles attached on top of the film. Increased film thickness could be reached using the direct growth approach by increasing the reaction time (e.g., from 63 to $111 \mathrm{~nm}$ after increasing the reaction time from 18 to $50 \mathrm{~min}$ ), which also leads to an increased number of agglomerated particles on the surface.

A similar approach as the direct growth via Yamamoto coupling was described by Kiriy and co-workers as the surface initiated polymerization approach. Using an Ni-catalyzed surface initiated Kumada catalyst-transfer polycondensation of a tetrafunctional thiophene-based $(\mathrm{AB})$ 2-monomer thin-film $(\approx 30 \mathrm{~nm})$ of POPs could be prepared on organosilica microparticles. ${ }^{[123]}$ An important feature of the developed process is that the polymerization of the monomer proceeded only from the surface where the catalyst is bound, but not in the bulk solution so that the formation of unbound POPs does not occur. Another approach to create POP films on surfaces is the layer-by-layer (LbL) method.

LbL Method: In the LbL method a functionalized surface is exposed to the molecular building blocks of a bicomponent POP system in an alternating fashion. Thereby the film is grown linearly with a thickness depending on the number of growth cycles with controllable thickness in the range of less than $10 \mathrm{~nm} .{ }^{[124]}$ The LbL approach was applied using different click chemistries $^{[125]}$ and allows to change the reaction type in different layers if orthogonal chemistries are used for the different layers. ${ }^{[126]}$ The LbL method also allows synthesis on sacrificial substrates that leads to create freestanding nanomembranes which showed to be highly selective in gas separation. ${ }^{[127]}$ Figure 6 shows the LbL synthesis on functionalized surfaces as well as the preparation of freestanding nanomembranes.

Electro Polymerization: $\mathrm{Ma}$ and co-workers reported a novel strategy to fabricate POP network films electrochemically, and highlight the application of POP films in electronic devices. ${ }^{[128]}$ Afterward several groups have also reported the synthesis of POP thin films via electrochemical oxidative polymerization of rigid, multitopic monomers. ${ }^{[129]}$ Carbazole- and thiophenebased rigid monomers have been utilized as building blocks, forming microporous polymer films with relatively smooth surface morphology. In the electro polymerization method the precursors are oxidized electrochemically, forming reactive species which undergo coupling reactions at the electrode, thereby forming the cross-linked polymer network film on the electrode surface. The thickness of the POP films was controlled by repeating several oxidation reduction cycles and the films were obtained on substrates or as freestanding films with thicknesses ranging from several nanometers to several micrometers.

Later Jiang and co-workers demonstrated the electropolymerization of $\pi$-conjugated systems based on thiophene functional groups. ${ }^{[130]}$ The electropolymerization of thiophene units for the preparation of $\pi$-conjugated microporous polymer films is widely extendable to other thiophene-based monomers which may find applications in a wide variety of areas, such as
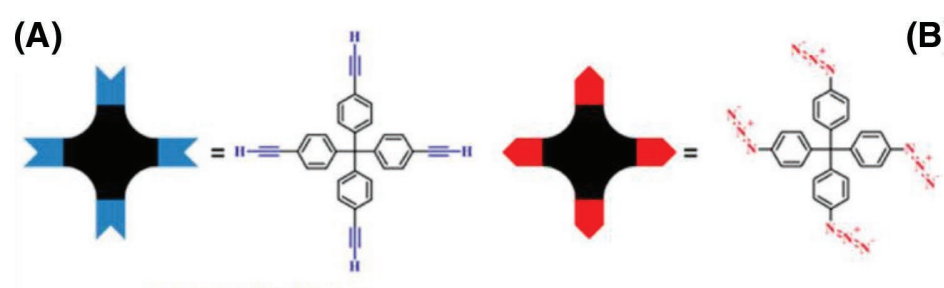

(B)
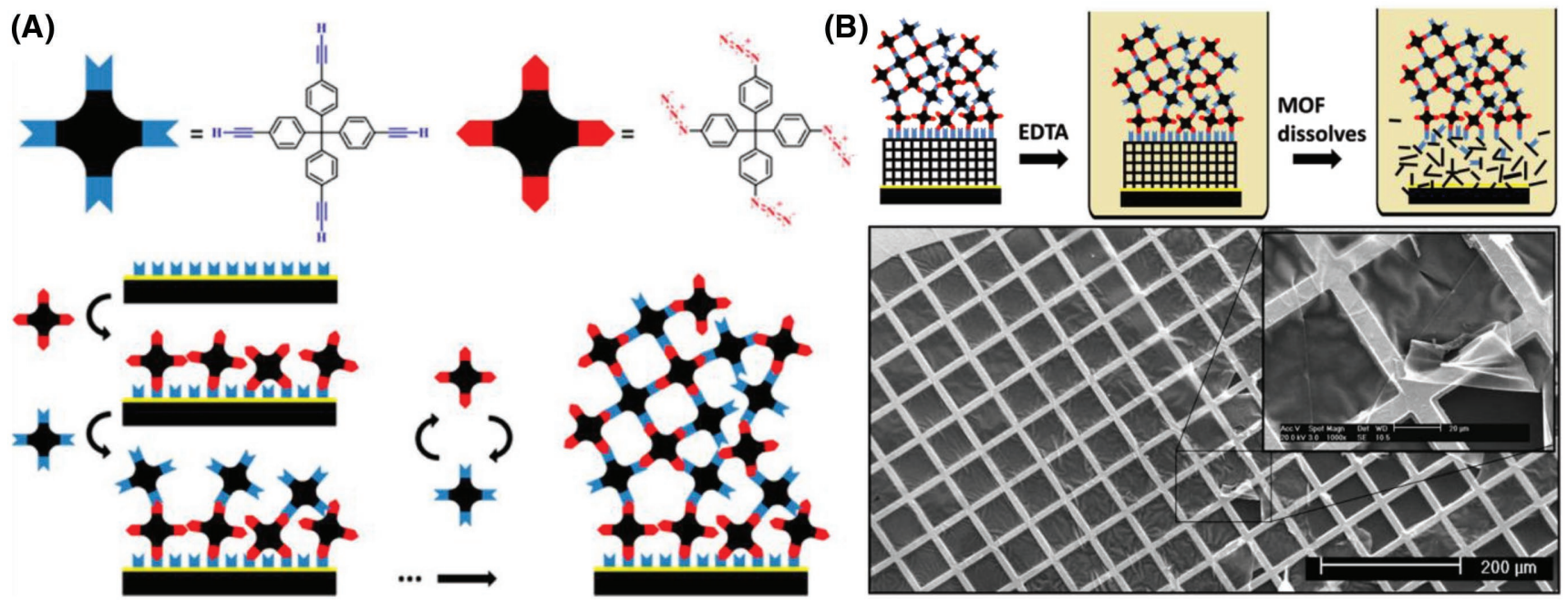

Figure 6. A) Molecular building blocks of the POP network system and schematic representation of their layer-by-layer synthesis on functionalized surfaces. B) POP networks on sacrificial substrates and subsequent dissolution of the substrate yielding in freestanding nanomembranes. All panels reproduced with permission. ${ }^{[124]}$ Copyright 2014, the American Chemical Society. 
transistors, diodes, vapor sensors, photoelectrochemical water splitting, and energy storage.

The electropolymerization technique has further been used to prepare thin films with advanced photophysical properties. ${ }^{[131]}$ Another interesting study by the group of Müllen and co-workers combined the advantages of dendrimers and electropolymerization. The dendrimer was composed of a central pyrene core and four exterior arms capped with electroactive triphenylamine. The obtained dendrimer films showed a rapidresponse, high sensitivity, and excellent reusability as fluorescence-film probes for 2,4,6-trinitrotoluene vapor, $\mathrm{Fe}^{3+}$ ions, and benzene vapor. ${ }^{[132]}$ In addition functional molecules such as porphyrins have been created using electropolymerization and applied as electrode material in supercapacitors. ${ }^{[133]}$

The electropolymerization approach has been applied by several groups to create thin films of POPs which were integrated in devices for various applications such as photoluminescence-based or electrochemical chemodetectors, electrochemical supercapacitors, and light-harvesting antennae for exciton pumping. ${ }^{[101]}$

Despite the wide range of possible applications and promising results, the electropolymerization approach is naturally restricted to monomers which can be electropolymerized. In addition, the polymer/electrode interface is not well controlled which could lead to detachment of the thin films. Even though for some electrocatalytic or organic electronic applications the stability of the thin-film attachment is essential, for membrane applications an easily detachable film could be advantageous.

In our general stance, POPs are a fascinating class of materials featuring high porosity combined with outstanding thermal and chemical stability. The past efforts on the design, synthesis and functional exploration have demonstrated that POPs are a versatile platform for structural and functional designs, which will continuously drive further advancement of this emerging field. However, certain efforts are required, the preparation methods have to be improved and alternative new protocols have to be developed for the improvement of their process-ability for successful applications. The challenge to prepare uniform thin films for their integration into novel devices has been overcome by several groups using different techniques ranging from rather straight forward approaches such as sol-gel or direct synthesis over layer-by-layer or microemulsion techniques toward more sophisticated techniques such as electro-polymerization. Further effort should be made to develop procedures that permit scalable preparation of porous organic polymers using environmental friendly and low- cost methods. As many POPs consist of extended conjugated backbones, applications in organic electronics and optical sensing of molecules or metal ions entering the porous framework have been frequently exploited. The high porosity and robust nature of the materials deems highly promising in gas and liquid phase separation. We anticipate a bright and promising future for POP thin films, with their utility as a powerful platform to achieve challenging environmental and energy related goals.

\section{Thin Covalent Organic Framework Films}

COFs are a class of hierarchical porous material formed by a covalent attachment of organic building units through reversible chemical reactions. ${ }^{[134,135]}$ This mode of assembly allows for a self-repair mechanism thereby endows COFs with the outstanding feature of structural long-range order. ${ }^{[136]}$ The synthesis of COFs is modular, and a careful selection of building units dictates their crystalline structure, the pore shape and size, and functionality. ${ }^{[137]}$ For instance, combining subunits of distinct planar character results in the formation of extended 2D polymer layers that undergo self-organization guided by weak interactions to form defined molecular columnar stacks yielding 1D ordered channels, the so-called 2D COFs. ${ }^{[136,138]}$ Employing building blocks of spatial character such as a tetrahedral carbon or a silicon results in the formation of 3D extended networks.

Commonly, COFs are synthesized under solvothermal conditions namely through condensation reactions in a solvent of high boiling point at elevated temperatures. ${ }^{[136]}$ Under these conditions, COFs are precipitated as an insoluble powder of intergrown crystallite microstructures. Therefore, COFs immobilization onto a surface requires meeting the strict synthesis conditions ensuring appropriate reaction rates permitting longrange order and permanent porosity in the process of a film growth. ${ }^{[139]}$ In this context, exploring the reaction paths under which COFs are formed has a great potential to assist in developing advanced procedures for the synthesis of COF thin films. An important aspect in the deposition of 2D COF films is the orientation of the COF crystallites on the surface. ${ }^{[140,141]}$ For applications requiring charge percolation and high pore accessibility a precise positioning of the COF layers parallel to the surface enables a direct path thought the overlapped $\pi$-system and beneficial open porous channels perpendicular to the surface. ${ }^{[142-144]}$ To date, a number of methods were reported for the growth of 2D COF on a verity of surfaces. However, some of these methods were reported for COF structures obtained by specific type of covalent link. Here, we will briefly overview the developed methods for COF films. We will discuss the different deposition approaches with respect to the COF chemical compositions, crystal structures and crystallites orientation on the surface and their utilization in different device platforms. In addition, we will present the preparation of free-standing COF films and their application.

Solvothermal, In Situ, Growth: In a typical solvothermal synthesis, the respective COF precursors are added to a mixture of organic solvents, producing homogeneous or heterogeneous reaction mixtures. Then, the reaction vessel is sealed and placed in a preheated oven for several days. COF powder material precipitates. The deposition of COFs as thin films under solvothermal conditions was first reported by Dichtel and coworkers. In that report, the bulk COF synthesis conditions were used without alterations for producing COF thin films. Immersing substrates decorated with a single layer of graphene (SLG) into the different synthesis mixtures, resulted in a thin COF deposit on the SLG along with COF powder precipitation in the reaction vessel (Figure 7). Using this method, several boronic ester-based COFs, such as the well-known hexagonal COF-5, ${ }^{[145]}$ consisting of 2,3,6,7,10,11-hexahydroxytriphenylene (HHTP) and 1,4-benzenediboronic acid, and a tetragonal, nickel-coordinated phthalocyanine containing NiPc-COF, were deposited on different SLG supported substrates such as fused silica, SiC or copper. Grazing incidence X-ray diffraction 

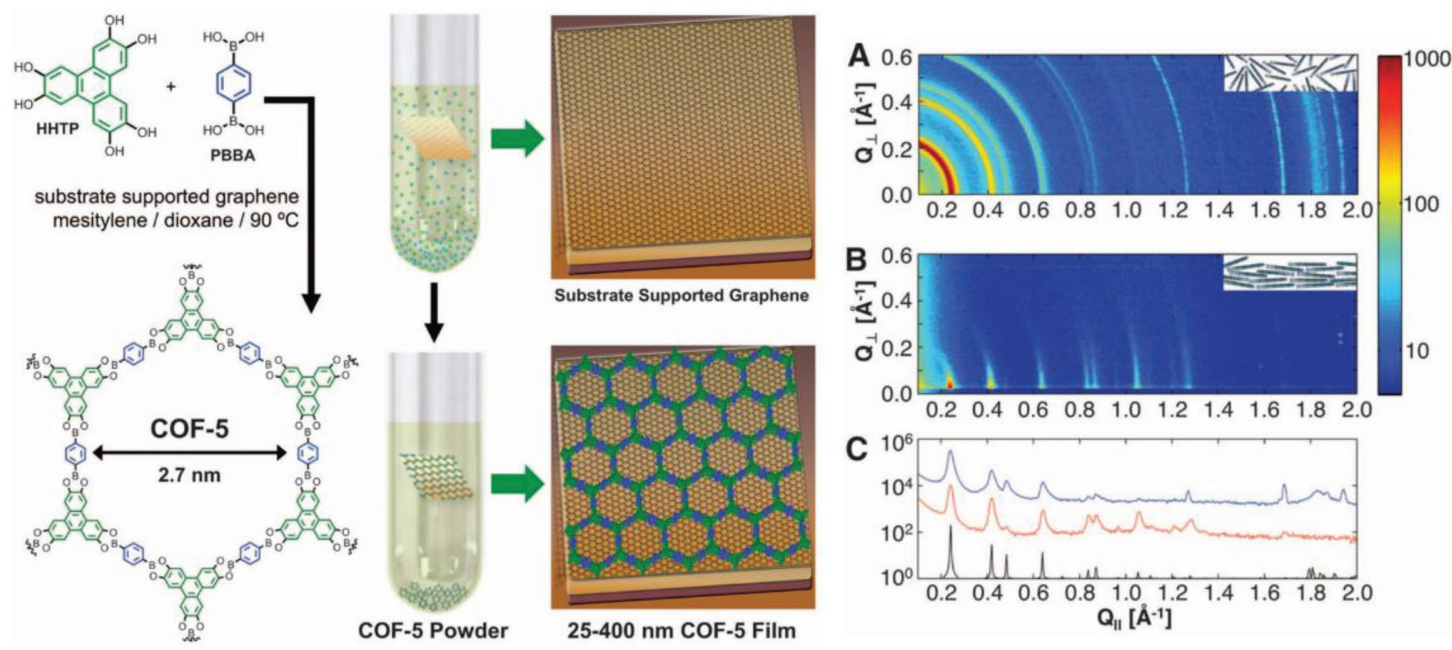

Figure 7. Left: solvothermal synthesis of COF-5 thin films by submerging a substrate-supported SLG surface into the reaction. Thereby, a film on the substrate surface, as well as powder, is obtained. Right: A) PXRD data as obtained from COF-5 powder. B) GIXRD data of an oriented COF-5 film grown on SLG/Cu. C) Projections of (A) (top/blue) and (B) (middle/red) near $Q_{\perp}=0$, and the simulated powder diffraction spectrum (bottom/black) for COF-5. Reproduced with permission. ${ }^{[140]}$ Copyright 2011, American Association for the Advancement of Science.

(GIXRD) studies revealed that the COF crystallites in the film were oriented with the layers deposited parallel to the substrate (Figure 7). The films exhibited high uniformity namely, a large area substrate coverage and thicknesses ranging from about $220 \mathrm{~nm}$ down to $70 \mathrm{~nm}$. Using the COF films on optically transparent SLG/ fused silica allowed additional access to higher resolved optical absorption and emission spectra of the COFs compared to previous diffuse reflectance measurements of bulk material. ${ }^{[140]}$

In subsequent reports Dichtel and co-workers generalized the in situ epitaxy synthesis route by demonstrating the synthesis of transferring it to several other tetragonal and hexagonal COF films. Different zinc containing pthalocyanine (ZnPc) $\mathrm{COFs}$ were synthesized on $\mathrm{SLG} / \mathrm{SiO}_{2}$ with pore sizes ranging from 2.7 to $4.4 \mathrm{~nm}$ and the hexagonal HHTP-DPB COF, comprising 4,4'-diphenylbutadiynebis(boronic acid) (DPB), with a pore size of $4.7 \mathrm{~nm}$ was demonstrated. ${ }^{[146]}$

Later, Dichtel and co-workers illustrated the selective growth of COF films on lithographically patterned SLG/fused silica. Employing the general solvothermal synthesis protocol developed for oriented thin-film synthesis of boronate ester COFs, namely performing the COF film synthesis in the appropriate solvent mixture consisting of dimethylacetamide and o-dichlorobenzene, film formation occured unselectively on all exposed surfaces, e.g., SLG functionalized and nonfunctionalized fused silica substrates. By employing a different solvent mixture for the film synthesis, namely methanol and 1,4-dioxane, a selective growth of the COF film on the SLG modified fused silica was achieved. The authors postulated that within the absence of an aromatic solvent, the large $\pi$-systems containing precursors readily adhere to the SLG from whereon film formation is promoted. ${ }^{[147]}$

Bein and co-workers demonstrated the growth of an electrondonor consisting of boronic acid-based benzodithiophene, BDT$\mathrm{COF}$, as highly oriented films on nonmodified, polycrystalline surfaces, such as gold, indium-doped tin oxide (ITO) or glass by the solvothermal in situ synthesis route. In that work, the pore accessibility of the COF films was assessed for the first time by krypton sorption measurements, revealing a surface area of $175 \mathrm{~cm}^{2} \mathrm{~cm}^{-2}$. Subsequently, the porous BDT-COF films were infiltrated with acceptor molecules, such as [C70]PCBM and the successful incorporation was illustrated by a significant photoluminescence (PL) quenching. The dynamics of COF photogenerated hole-polarons was further studied by transient absorption spectroscopy showing an elongation of the radical cation life-time upon the incorporation of acceptor phase into the thin COF films. Additionally, insights into the BDT-COF film growth process were provided by halting the film synthesis at different times. Ending the synthesis prematurely revealed that film formation occurs through an island growth mode, the formed COF island continue to grow with progressing synthesis time to form a continuous film (Figure 8). ${ }^{[139]}$

In a subsequent study, highly oriented thin BDT-COF films were grown on semiconducting substrates allowing for studying the directional charge-carrier transport along the molecular columns of the $\pi$-stacked COF layers and in transverse direction. The hole-mobility along the BDT-COF molecular stacks was evaluated by constructing hole-only devices (HODs) in a diode configuration where the BDT-COF film served as an active layer between hole-selective MoOx layers (Figure 9). $I-V$ characteristics of the HODs revealed that the hole-mobility along the stacked COF layers is dependent on film thickness with a two order of magnitude higher value in hole-mobility $\left(3 \times 10^{-7} \mathrm{~cm}^{2} \mathrm{~V}^{-1} \mathrm{~s}^{-1}\right)$. Using the well aligned COF layers parallel to the surface, in-plane electrical conductivity measurements of the BDT-COF grown on glass modified with interdigitated gold electrodes showed a conductivity value of $5 \times 10^{-7} \mathrm{~S} \mathrm{~cm}^{-1}$, where the large resistance was attributed to the nonconjugated boronate ester linkage. Nevertheless, the measured in-plane conductivity value for the oriented BDT-COF thin films is three orders of magnitude higher than the value measured for a BDT-COF pressed pellet. ${ }^{[148]}$

Bein and co-workers reported on the synthesis of boronate-ester linked thienothiophene-based TT-COF showing an 

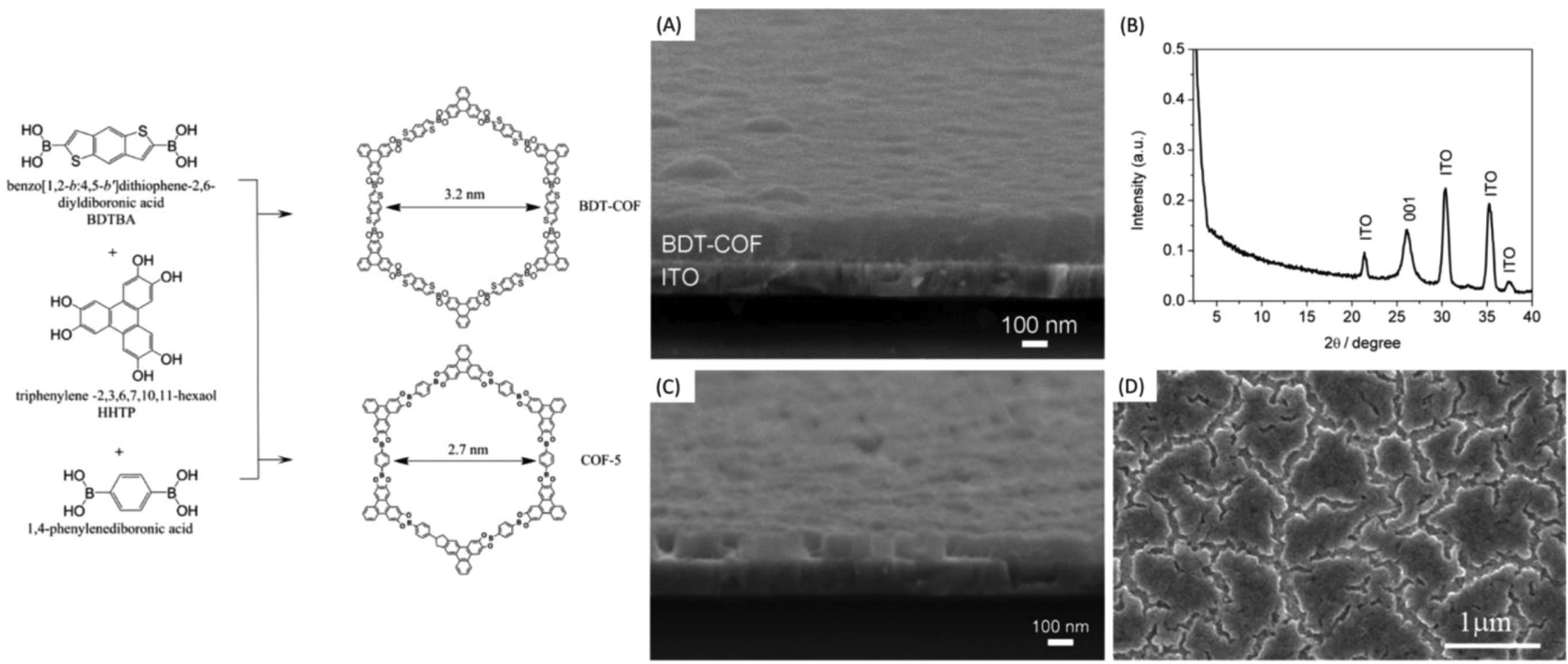

Figure 8. Left: reaction scheme for the synthesis of BDT-COF and COF-5 used for the vapor-assisted conversion film synthesis. Right: A) SEM microscopy images of BDT-COF grown on ITO. B) X-ray diffraction pattern of BDT-COF film grown on ITO-coated glass at a low incidence angle. SEM images of BDT-COF films synthesized at shortened reaction times in C) cross-section and D) top view. All panles reproduced with permission. ${ }^{[139]}$ Copyright 2014, the American Chemical Society. Published under an ACS AuthorChoice license.

efficient charge transfer to an infiltrated fullerene acceptor phase. The TT-COF films were integrated into a photovoltaic device with ITO/TT-COF:PCBM/Al architecture. A power conversion efficiency of $0.053 \%$ and an external quantum efficiency of $3.4 \%$ were measured for the device. Later, TP-COF consisting of linear porphyrin and HHTP building blocks forming discret donor-acceptor stacks segregated by the nonconjugated boronate ester bond resulting in a COF integral heterojunction was synthesized as an oriented thin film. In the oriented film, the donor-acceptor stacks are arranged in an optimal way enabling charge transfer and subseqently to transport to the respective selective electrodes. Using a ITO/ $\mathrm{MoO}_{x} / \mathrm{COF} / \mathrm{ZnO} / \mathrm{Al}$ device layout charge carriers were extracted, and the successful design was proven by an external quantum efficiency of 30\% upon applying an external bias. ${ }^{[142]}$

Dichtel and co-workers expanded the in situ COF film synthesis to the chemically stable $\beta$-ketoenamine linkage motif. A DAAQ-TFP COF, containing redox-active anthraquinone moieties and 1,3,5-triformylphloroglucinol (TFP) was grown as an oriented film on gold electrodes for charge-storage application. The oriented COF film featured a $400 \%$ increase in capacitance compared to electrodes functionalized with bulk COF material, ${ }^{[149]}$ which was attributed to the improved interfacing between the electrode and the oriented COF film. A high capacitance value of $3.0 \mathrm{mF} \mathrm{cm}^{-1}$ was measured for the DAAQ-TFP $\mathrm{COF}$ and galvanostatic charge-discharge experiments showed the high cycling stability of the COF films. ${ }^{[150]}$

Multilayered structures consisting of oriented $\beta$-ketoenamine linked COF thin films and conducting electrodes were fabricated by $\mathrm{Lu}$ and co-workers. For the multilayered structure, an oriented $\beta$-ketoenamine linked COF film was grown on an ITO substrate subsequently the exposed COF film was coated with platinum metal via sputtering and an additional COF layer was grown on the newly exposed platinum layer under solvothermal conditions featuring an alternating stacked of metal/ COF structure. ${ }^{[151]}$

The in situ approach was found to be a suitable route for the synthesis of stable imine-linked COFs. Liu and coworker synthesized oriented thin films of the imine-linked tetrathiafulvalene containing the TTF-COF. The electrical conductivity for this $\mathrm{COF}$ was assessed by growing oriented films on nonconductive glass substrates decorated with two gold electrodes. Two-point probe in-plane conductivity measurements were carried out on an oriented TTF-COF film revealing an electrical conductivity
(A)

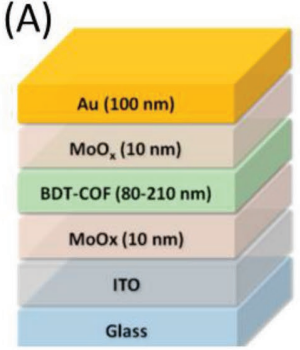

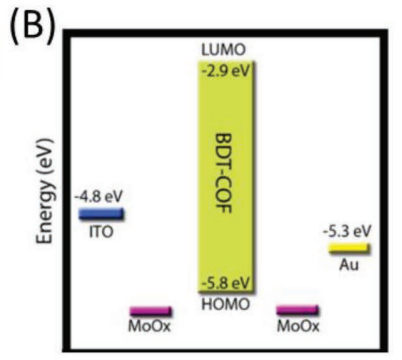

(C)

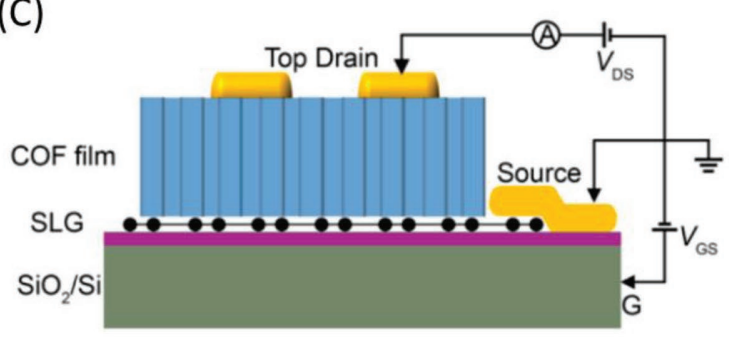

Figure 9. Schematic representation of A) BDT-COF hole-only device layout and B) the corresponding energy diagram. A,B) Repoduced with permission. ${ }^{[148]}$ Copyright 2017, American Chemical Society. C) Vertical field-effect transistor layout for a COF/SLG/SiO2/Si device. C) Reproduced with permission. ${ }^{[144]}$ Copyright 2017, American Chemical Society. 
Surface Adsorption and Nucleation

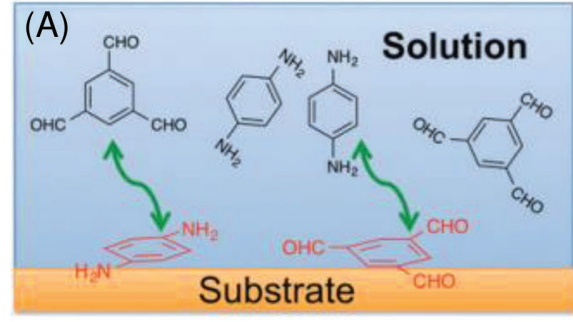

Reorganization and Further Growth

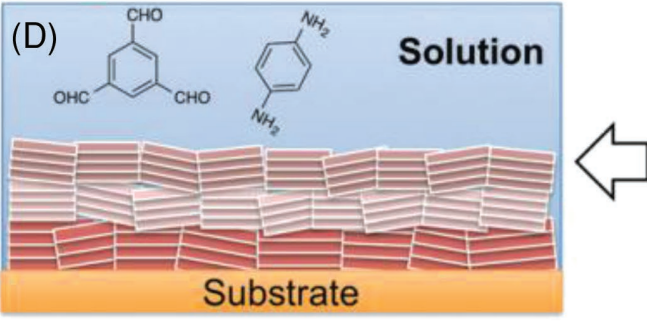

Surface Layer Growth

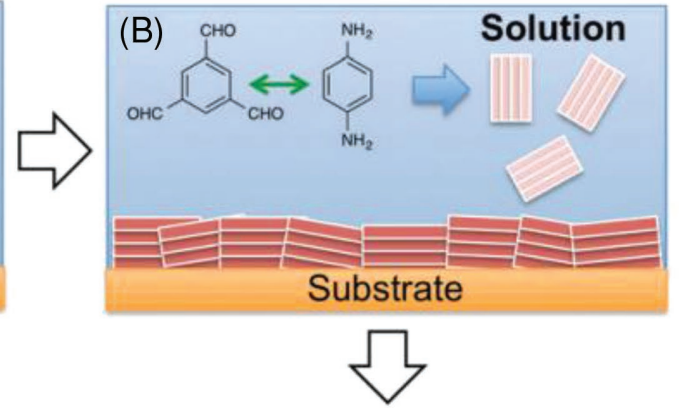

Solution Growth and Deposition

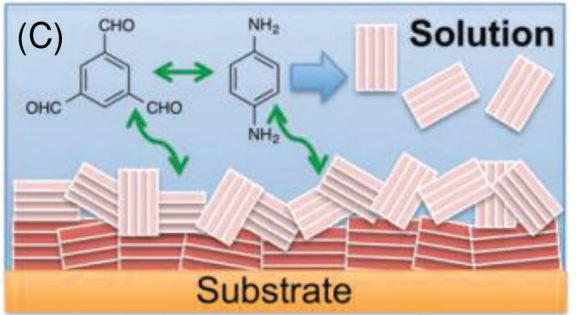

Figure 10. Illustration of the different film growth stages. A) Surface adsorption of precursor molecules and nucleation. B) Surface layer growth. C) Solution crystallite growth and deposition on top of previous surface layers. D) Reorientation of solution deposited crystallite layers and further growth. The green double-headed arrows indicate reactions between different species. All panels reproduced with permission. ${ }^{[141]}$ Copyright 2017 , the Royal Society of Chemistry.

values of $1.2 \times 10^{-6} \mathrm{~S} \mathrm{~cm}^{-1}$ for the pristine film which was increased by two orders of magnitude, upon iodine doping. [152]

A vertical field effect transistor using a COF consisting of pyrene and terephthalaldehyde was constructed by growing an oriented thin film on a $\mathrm{SLG} / \mathrm{SiO}_{2} / \mathrm{Si}$ substrate. The transistor device was completed by evaporating two gold electrodes serving as the source and drain on top of the COF films (Figure 3). The device showed ambipolar transport and on-current densities of over $4.1 \mathrm{~A} \mathrm{~cm}^{-2}$. Since the device performance was found to be strongly linked to film thickness, thin films of $50 \mathrm{~nm}$ and less were used to create short channel lengths. The COF measured behaved as p-type transistor with high on-current densities for holes of 6.8 and $4.1 \mathrm{~A} \mathrm{~cm}^{-2}$ for electron transport. ${ }^{[144]}$

Very recently, Bein and co-workers reported the synthesis of oriented PyTII COF films containing of the near-infrared (NIR) dyes isoindigo or thieno-isoindigo, and a pyrene building block. These films were used to construct a photodetector showing an invertible spectral sensitivity. A device layout of ITO/MoO $/$ COF:[C71]PCBM/PFN/Ag was chosen, by applying an external bias, the spectral sensitivity toward incident light could be changed from blue and red to an enhanced response in the green and NIR absorption regions. ${ }^{[153]}$

An imine-linked COF thin film, containing the photoactive benzodithiophene and tetraphenylethylene building blocks, was used as a novel type of photoelectrode by Bein and co-workers. The high absorbance of visible light allowed for the generation of photo-excited electrons which were used for proton reduction and hydrogen evolution in aqueous electrolytes. The COF photocathode showed high corrosion stability and steady performance over several hours of operation. ${ }^{[154]}$

In the context of electrocatalytical performance of COFs Yaghi and co-workers introduced a series of cobalt porphyrin containing COFs for the electrocatalytic reduction of $\mathrm{CO}_{2}$ to CO. The growth of these COFs as oriented films directly on the substrate showed a significant advantage compared to the performance of bulk material, deposited on a conductive carbon fabric, attributed to the enhanced contact between the electrodes and the COFs. The reduction reactions showed high selectivity and current densities and could be performed at low overpotentials. ${ }^{[155,156]}$

Very recently Yaghi and co-workers employed a different strategy for the fabrication of a weaving COF, COF-112, using a protected building block in a homogeneous reaction mixture. The in situ deprotection of the BOC protecting groups by trifluoroacetic acid slowed down the imine condensation reaction and facilitate the crystallization of COF-112. Adapting this approach for the thin-film synthesis, oriented films of the imine-linked LZU-1 framework, consisting of 1,3,5-triformylbenzene and 1,4-diaminobenzene, were grown from the homogeneous precursor solutions yielding uniform films of $190 \mathrm{~nm}$ in thickness within $2 \mathrm{~h}$. Optical characterizations via ellipsometry were carried out for the first time on a COF film where a high refractive index of 1.83 at $632.8 \mathrm{~nm}$ was found, which hints towards a strong in-plane conductivity of the obtained films. ${ }^{[157]}$

A systematic study of thin imine-linked LZU-1 COF films growth by the solvothermal approach was conducted by Liu and co-workers (Figure 10). The formation of crystalline COF films was studied with relation to the COF precursor concentrations and duration of the film synthesis reaction. Systematic GIXRD studies showed that film formation occurs through two main steps. First, oriented material is deposited on the substrate and subsequently a disoriented phase from solution adheres on top of this layer. The nonoriented phase then reorganizes 
through an interface-initialized templating effect between the formerly deposited, oriented crystallites and the nonoriented material. The reorientation step was indicated by the authors as the majorly contributing mechanism of oriented COF film growth. Time-dependent GIWAXS studies showed an almost linear increase in film thickness up to the first $48 \mathrm{~h}$ of the film synthesis and that the rate of growth is highly dependent on COF precursor concentration. High precursor concentrations lead to significantly faster reaction rates and an increase in film thickness compared to lower concentrations. Additionally, a more pronounced disoriented phase could be observed during film formation at higher concentrations, indicating a kinetically formed, metastable phase. ${ }^{[141]}$

Direct Deposition of COF Thin Films, Vapor-Assisted Conversion (VAC): The in situ thin-film synthesis paved the way for the study of COF film in form of a device. However, a few aspects such as scalability, control over the film morphology, preventing undesired secondary nucleation from solution are still challenging. To address these issues, several other film synthesis methods have been developed mainly aiming at a direct deposit COF material onto a surface.

Bein and co-workers developed a room temperature VAC protocol suitable for the synthesis of COF films. In a typical VAC synthesis, the respective COF building blocks are dissolved in a mixture of polar low boiling point solvents which are subsequently drop-cast onto various substrates. Then, the cast substrates are transferred into a reactor equipped with a vessel containing low vapor pressure solvents such as mesitylene and 1,4-dioxane. Upon a tight sealing of the reactor, the arising vapor atmosphere of the solvents in the reactor assist the conversion of the drop-cast precursor solutions into a crystalline COF phase within $3 \mathrm{~h}$. Through VAC, highly crystalline COF films of boronic ester and boroxine linkages were obtained. The films feature random COF crystallite orientation in the film and homogeneous growth and coverage over the whole substrate. By altering the drop-cast precursor solution volumes and concentrations in the droplet film thicknesses ranging from $300 \mathrm{~nm}$ to $7.5 \mu \mathrm{m}$ were obtained. Additionally, a thickness dependent morphology of the films was found in which thin films show a dense morphology of intergrown COF crystallites suitable for device fabrication and thicker films show an additional textural porosity between COF particles (Figure 11). The VAC synthesis route illustrates the direct deposition of COF building blocks on a surface and a quantitative conversion into the respective crystalline frameworks. ${ }^{[158]}$

Continuous Flow Growth: A continuous flow growth approach was developed by Dichtel and co-workers featuring a direct film deposition on a substrate. In this report, homogeneous precursor solutions are pumped through a heated tubing for specific retention times. Thereby, the precursors polymerize within the tubing, forming oligomers, and are subsequently passed over a substrate where they adhere and crystallize into COFs. Through this growth approach, several boronic ester linked frameworks were synthesized and deposited as crystalline and oriented materials within several minutes. Keeping the precursor concentrations constant through the continuous flow, linear deposition rates were achieved which allowed for a better control over the film thickness, this was studied by depositing the COFs directly on QCM chips and monitoring the mass increase on the chip. ${ }^{[159]}$
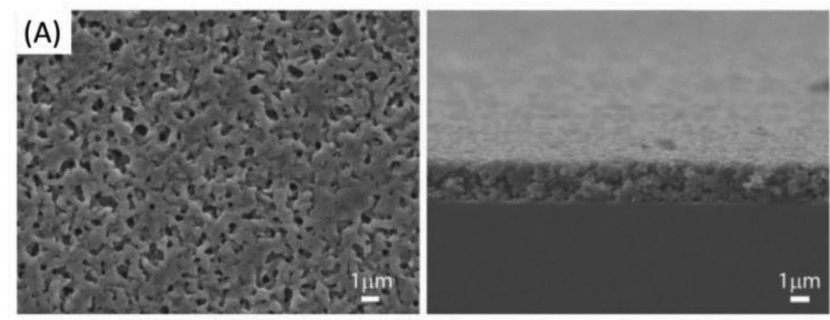

(B)
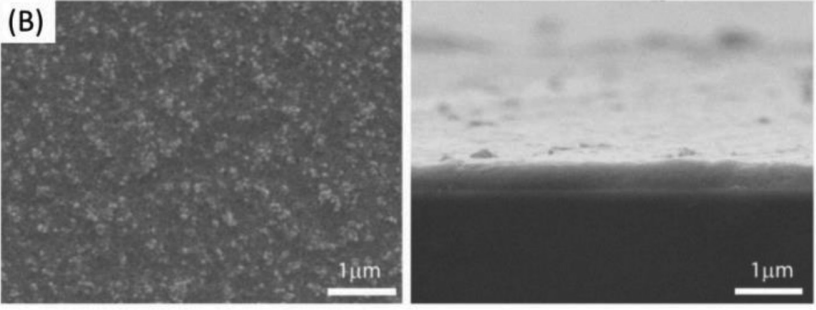

Figure 11. BDT-COF films prepared by vapor-assisted conversion on glass as top views (left) and cross-sections (right). A) Films of $2 \mu \mathrm{m}$ thickness revealing the textural porosity between intergrown particles. B) Thin films of $300 \mathrm{~nm}$ showing a dense morphology. All panels reproduced with permission. ${ }^{[158]}$ Copyright 2015, the American Chemical Soceity. Published under an ACS authors choice license.

Free-Standing COF Films: Bao and co-workers synthesized COF films of an imine-linked dialkoxy benzodithiophene COF at the solution/air interface at room temperature. Altering the COF growth time yielded films of different thickness ranging from 2 to $200 \mathrm{~nm}$. The material was transferred as a freestanding film by extraction from the growth solution onto a substrate. The authors discovered that by using this particular synthesis method as opposed to a more conventional solvothermal film synthesis, the roughness of the film was decreased, however, the crystallinity and crystallite orientation in the film were affected. The synthesized COF film was characterized in a top-contact transistor device and showed characteristics of organic FET behavior with measured hole mobilities of $3.0 \times 10^{-6} \mathrm{~cm}^{2} \mathrm{~V}^{-1} \mathrm{~s}^{-1} \cdot{ }^{[160]}$

Banerjee and co-workers introduced a new strategy for the preparation of $\beta$-ketoenamine linked COFs as free-standing porous COF membranes. In this scalable process, a paste of molecular precursors is ground and knife-casted onto substrates and subsequently heated in an oven. Thereby, flexible, thick free-standing COF films of 200-700 $\mu \mathrm{m}$ were synthesized as defect- and crack-free membranes. The obtained films were used for molecular sieving applications featuring a high selectivity towards polar organic solvents. ${ }^{[161]}$

A further development to use COFs for the construction of membranes was subsequently demonstrated by Banerjee and co-workers. Here, COFs were grown as films at a liquid/ liquid interface between water and an organic solvent. By dissolving one precursor in the organic phase and introducing the second one as an ammonium salt through the water phase, $\beta$-ketoenamine linked COFs could be synthesized as freestanding thin films with thicknesses ranging from 50-200 nm which were readily transferable to substrates and could be used as selective molecular sieves for organic solvents. ${ }^{[162]}$

Following up on the liquid/liquid interface growth, Dichtel and co-workers synthesized imine-linked COF films by using a 
scandium triflate catalyst in the aqueous phase and the organic linkers dissolved in the organic phase. Thereby, depanding on the initial concentration of the precursors in the organic phase films with thicknesses ranging from $2.5 \mathrm{~nm}$ to $100 \mu \mathrm{m}$ were fabricated. ${ }^{[163]}$

Spin-Coating and Drop-Casting COF Suspensions: In addition to the direct synthesis as substrate-supported or free-standing films, COF thin films were fabricated through a post-synthesis direct casting of COF suspensions in organic solvents on a surface. Using this method, boronic-ester-based porphyrin COF films of $1.5 \mu \mathrm{m}$ thickness were prepared as an active material on ITO and contacted to an Al electrode. For these films, the number of photoinduced charge carriers was assessed via timeof-flight (TOF) measurements. The frameworks showed charge carrier generation yields in the range of $10^{-5}$ with respect of generated charge carriers per incident photon and TOF transient current integration measurements revealed a hole mobility of $10^{\circ} \mathrm{cm}^{2} \mathrm{~V}^{-1} \mathrm{~s}^{-1}$. Using this deposition method in combination with TOF measurements, charge carrier generation and hole mobilities were measured for a several boronic ester and imine-linked frameworks. ${ }^{[164-166]}$ Furthermore, a photovoltaic device was constructed by Jiang and co-workers using COF powder combined with [C60]PCBM, which was spin-coated as a $100 \mathrm{~nm}$ thin film onto ITO. The evaporation of an electron selective Al layer on top of the COF@[C60]PCBM completed a solar devices featuring a power conversion efficiency of $0.9 \%$ and a large open-circuit voltage of $0.98 \mathrm{~V} .^{[167]}$

Dichtel and co-workers showed the fabrication of freestanding COF films of COF-5 with preferential crystallite orientation by solution casting of stable colloidal COF particles. The material was deposited in the form of a colloidal mixture of crystalline COF particles in an organic solvent onto a substrate. Upon solvent removal at elevated temperature, the particles aggregated, resulting in a free-standing film, which readily cleaves from the substrate. The COF crystallites in the film show a preferential orientation in which the COF layer stacking direction is perpendicular to the substrate. ${ }^{[168]}$

\section{Controlled Synthesis of Nanoporous Carbon Thin Films and Applications in Chemical Energy Management}

Thin Films of Ordered Carbon Nanostructures: Inorganic, $\mathrm{sp}^{2}$-based carbon materials are composed of an expanded system of conjugated $\pi$-electrons and thus provide several outstanding physicochemical properties. Obvious examples of such physicochemical properties are high mechanical stability, thermal resistance, and chemical inertness. Nanostructuring of these materials leads to the quantum confinement of electrons in one or more dimensions and thus novel electrical, optical, or magnetic properties are accessible. Such carbon nanomaterials can be OD (e.g., carbon nanoparticles, fullerenes, or carbon onions), 1D (e.g., carbon nanotubes or carbon nanofibers), or 2D (graphene).

In principle, graphene is the basic building block for all other $\mathrm{sp}^{2}$-based carbon allotropes. With its atomically thin layer of atoms arranged in a honeycomb lattice it is of course the thinnest layer of carbon we can imagine. Graphene shows unusual mechanical strength, high heat conductivity, high transparence and electrical conductivity. Due to these unique properties, nanometer-thin films of graphene and its "well-ordered" derivates (e.g., carbon nanotubes to mention one prominent example) attracted considerable amounts of attention for their application in different electronic devices. ${ }^{[169]}$ Synthesis methods (e.g., direct growth, solution-based deposition, or printing) ${ }^{[169,170]}$ as well as corresponding structures of thin films of well-ordered carbon materials and their possible applications (e.g., transistors, ${ }^{[170-172]}$ energy storage, ${ }^{[173]}$ transparent electronics, ${ }^{[174,175]}$ and others) are of high importance and their number is growing rapidly, but they are not within the scope of this section.

Nanoporous Carbon Materials: An emerging $\mathrm{sp}^{2}$-rich carbon allotrope with a rather random and disordered nanostructure that has a high surface area is nanoporous carbon. ${ }^{[176]}$ Their specific surface area can achieve $3000 \mathrm{~m}^{2} \mathrm{~g}^{-1}$ and more and the carbon atoms are arranged in a random structure, which is in most cases X-ray amorphous. These materials contain narrow pores with diameters below $100 \mathrm{~nm}$ located in a structure often composed of disordered assemblies of small defective polyaromatic units. The presence of these defects (e.g., non-6-membered rings, heteroatoms, or simply missing carbon atoms) within the hexagonal carbon lattice of the single graphene-like sheets causes strains and nonplanar geometries. This leads to the formation of narrow porosity. ${ }^{[177]}$ Due to their high internal specific surface area combined with electrical conductivity and chemical inertness, such materials are highly attractive for application in an array of energy and environmentally relevant fields (e.g., catalysis, ${ }^{[178]}$ electrochemical energy storage, ${ }^{[179]}$ or gas adsorption ${ }^{[180]}$ ).

Thin-film engineering of nanoporous carbons is a crucial aspect for many of those fields. ${ }^{[181]}$ In order to achieve optimum performance in the respective applications, not only the film thickness but also the pore size, pore geometry, pore connectivity, and carbon microstructure (e.g., the degree of graphitic ordering or the presence of heteroatoms/surface functional groups) must be precisely controlled. In this section we offer a brief overview of some of the recent important examples for synthetic approaches to produce thin films of carbon materials with well-defined nanopores in the micropore (diameter $<2 \mathrm{~nm}$ ) and mesopore (diameter $2-50 \mathrm{~nm}$ ) range on different substrates. A couple of significant examples for emerging applications of the respective thin films in fields dealing with chemical energy management will also be given. Notably, $\mu \mathrm{m}$-thick films of carbon nanotubes can also be considered as nanoporous thin films. ${ }^{[169]}$ Macroporous (diameter > $50 \mathrm{~nm}$ ) carbon films/ membranes ${ }^{[182]}$ are also promising in many fields but such structures will not be part of this review. Solely amorphous carbon nanostructures as well as microporous and ordered mesoporous thin films will be addressed due to their pore sizes which are located in the range of the other classes of materials discussed in this article. While we will concentrate on carbons obtained from rather "traditional precursors" it should also be mentioned that the conversion of many of the organic molecular porous materials discussed above is an emerging field of research $^{[183,184]}$ and studies on the production of carbon thin films by conversion of thin films of organic materials can be expected to increase in number in the near future. 
Thin Films of Well-Defined Microporous Carbons: Microporous carbon materials with pore sizes below $2 \mathrm{~nm}$ provide specific surface areas often exceeding $1000 \mathrm{~m}^{2} \mathrm{~g}^{-1}$ and the strong interaction with guest species in adsorption processes due to the confinement in the narrow cavities. However, in many applications the micropores can only be fully utilized if the entire surface area is rapidly accessible for the mobile species involved in the process. Besides the introduction of additional larger transport pores or downscaling of the particle size to the nanometer scale, ${ }^{[185]}$ engineering the microporous carbons as thin films is one way to enhance the accessibility of their surface and to increase volumetric efficiency in many cases.

One elegant strategy for the synthesis of microporous carbon thin films is the so-called carbide-derived carbon (CDC) approach. ${ }^{[186]}$ CDCs are mainly microporous carbon materials obtained by the removal of metal or semi-metal atoms from carbide precursors, most often by chlorine treatment at temperatures of $400-1200{ }^{\circ} \mathrm{C}$. For the synthesis of thin carbon films with well-defined micropores, titanium carbide can be deposited on a substrate followed by metal removal or it can act as the substrate itself if only the surface is chlorinated (Figure 12A). ${ }^{[187]}$ One advantage of this approach is its versatility in terms of the substrate. Different carbon materials (e.g., glassy carbon or pyrolytic graphite) but also other inorganic substances like alumina or silicon with silica layer (to protect the substrate from reaction with chlorine at high temperatures) can be utilized (Figure 12B). ${ }^{[188]}$ On the other hand, the conformal transformation of the carbide structure to the carbon material allows the precise adjustment of the thickness of the carbon layer by controlling the thickness of the carbide precursor layer on the substrate. The CDC process usually proceeds by a layer-by-layer mechanism and hence the thickness of the carbon can be controlled by the contact time with the chlorine gas if a carbide precursor is utilized as the substrate (Figure 12C). ${ }^{[187,189]}$ Such microporous carbon thin films with $0.8-1 \mu \mathrm{m}$ thickness on glassy carbon substrate have been applied as electrode material in electrical double-layer capacitors (EDLCs) and provide volumetric capacitance above $180 \mathrm{~F} \mathrm{~cm}^{-3}$ at $20 \mathrm{mV} \mathrm{s}^{-1}$ scan rate (in a $1.5 \mathrm{~m}$ solution of tetraethylammonium tetrafluoroborate in acetonitrile as the electrolyte). ${ }^{[188]}$ This value is three times higher compared to conventional carbon electrodes with comparable thickness produced from powder particles. Compared
(A)

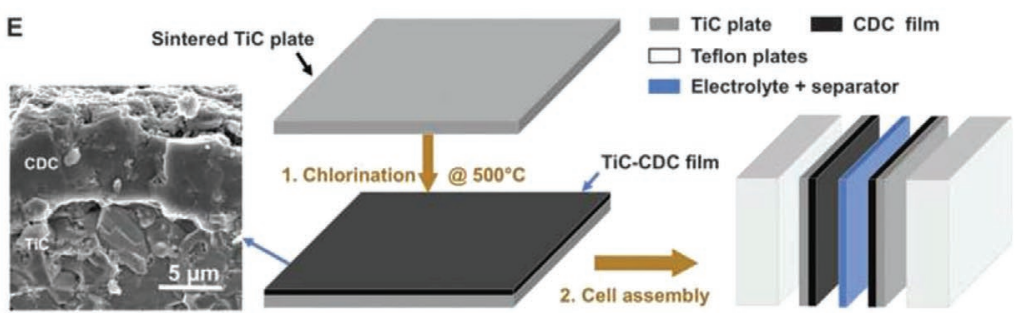

(B)
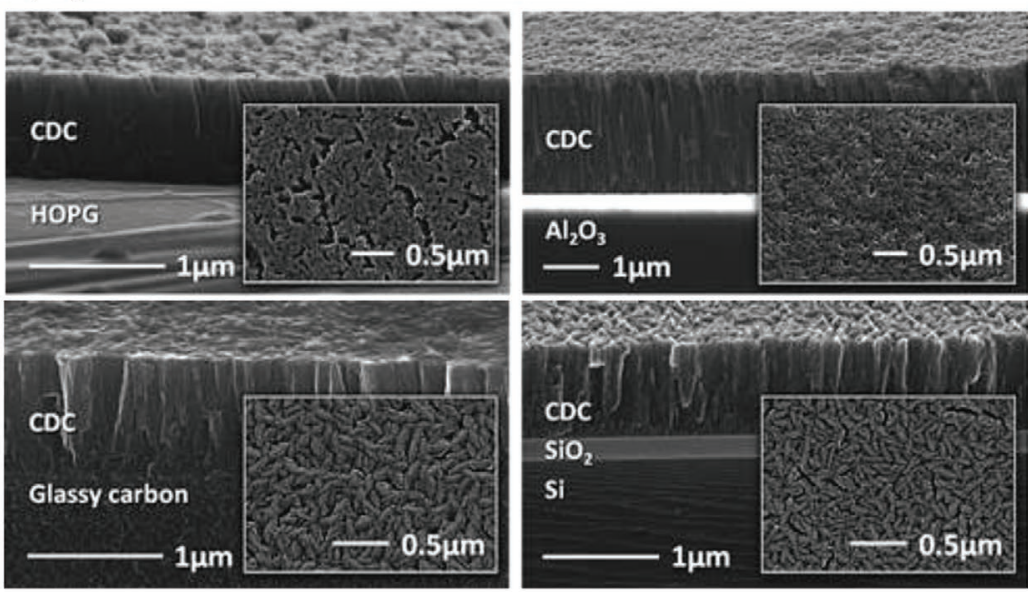

(C)
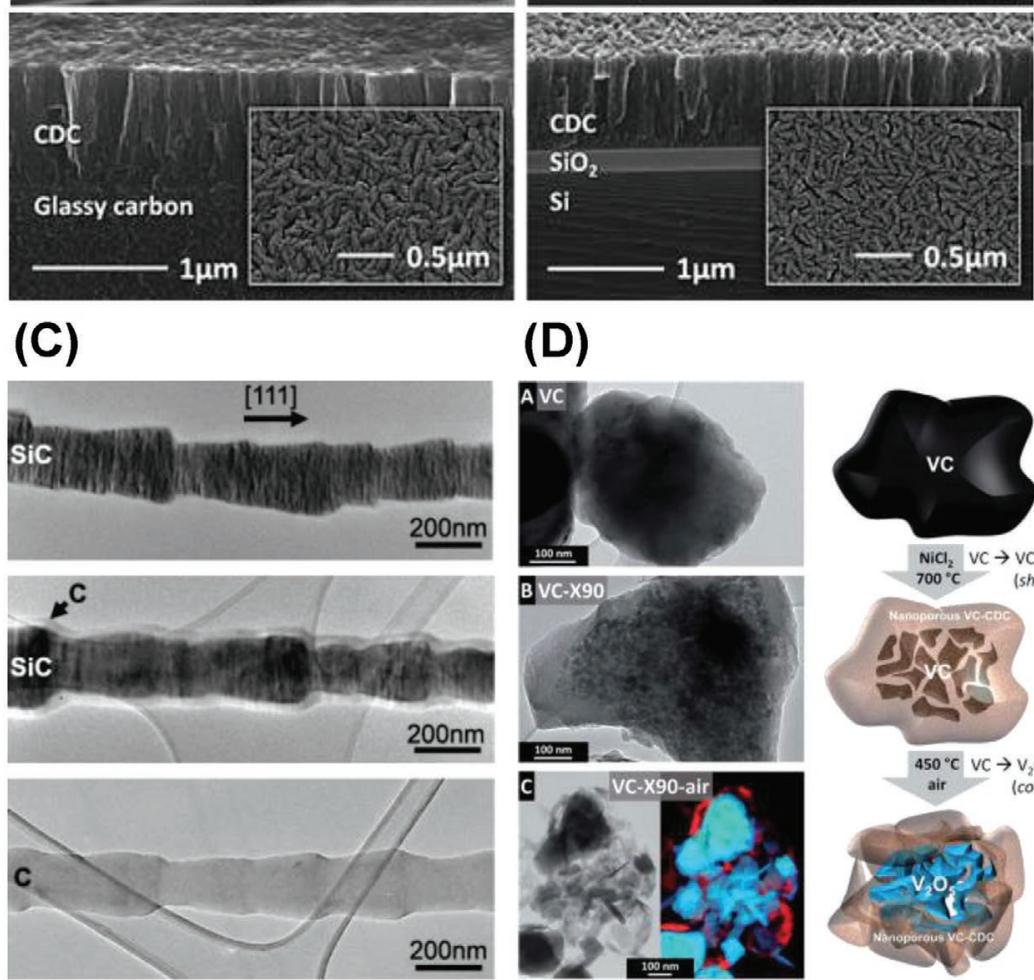

(D)
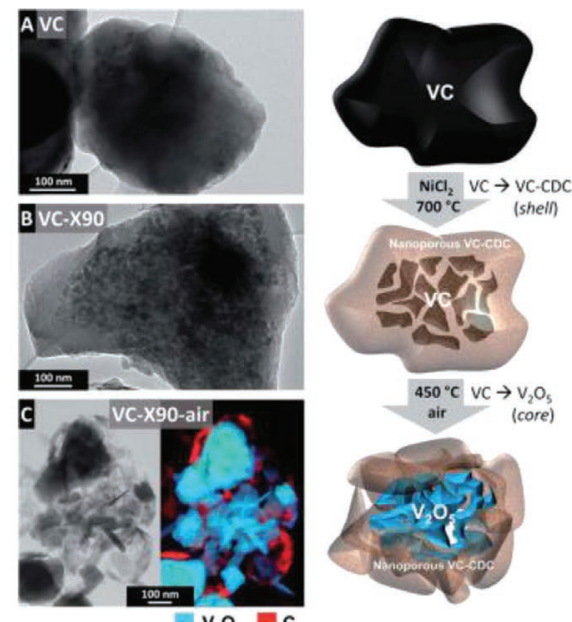

$\mathrm{V}_{2} \mathrm{O}_{3} \square \mathrm{C}$

Figure 12. A) CDC thin-film synthesis and EDLC test cell preparation. Titanium is extracted from titanium carbide as $\mathrm{TiCl}_{4}$, forming a porous carbon film. Two carbide plates with the same CDC coating thickness are placed face to face and separated by a polymer fabric soaked with electrolyte. The SEM image (left) shows a representative image of a CDC/TiC interface with a good film adhesion. Reproduced with permission. ${ }^{[187]}$ Copyright 2010, American Association for the Advancement of Science. B) SEM images of CDC films on highly ordered pyrolytic graphite (HOPG) produced at $500^{\circ} \mathrm{C}$, on $\mathrm{Al}_{2} \mathrm{O}_{3}$ produced at $400{ }^{\circ} \mathrm{C}$, on glassy carbon produced at $300{ }^{\circ} \mathrm{C}$, and on oxidized Si wafer produced at $300{ }^{\circ} \mathrm{C}$. Reproduced with permission. ${ }^{188]}$ Copyright 2010, Royal Society of Chemistry. C) TEM images of SiC whiskers at different stages of the transformation to carbon: top: pristine $\mathrm{SiC}$ whisker, middle: partially carbon-coated $\mathrm{SiC}$ whisker, and bottom: whisker completely transformed to porous carbide-derived carbon. Reproduced with permission. ${ }^{[189]}$ Copyright 2006, The American Ceramic Society. D) TEM images and schematic illustration of the transformation process from vanadium carbide to $\mathrm{V}_{2} \mathrm{O}_{5} / C D C$ core-shell particles. The bottom panel shows the TEM image (filtered $5 \mathrm{eV}$ around the zero loss peak) and the corresponding chemical EELS mapping. Reproduced with permission. ${ }^{[190]}$ Copyright 2016, the Royal Society of Chemistry. 

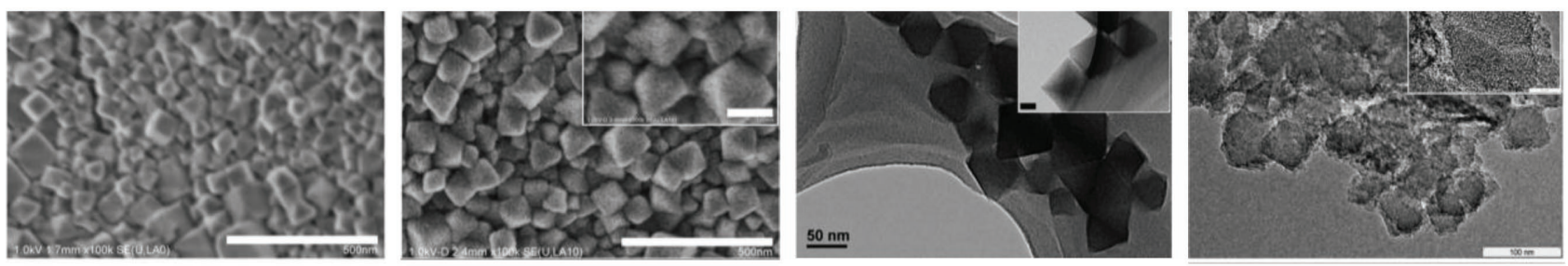

(B)

Nanocarbon Surface Engineering: From Monopolar to Bipolar Amphiphile
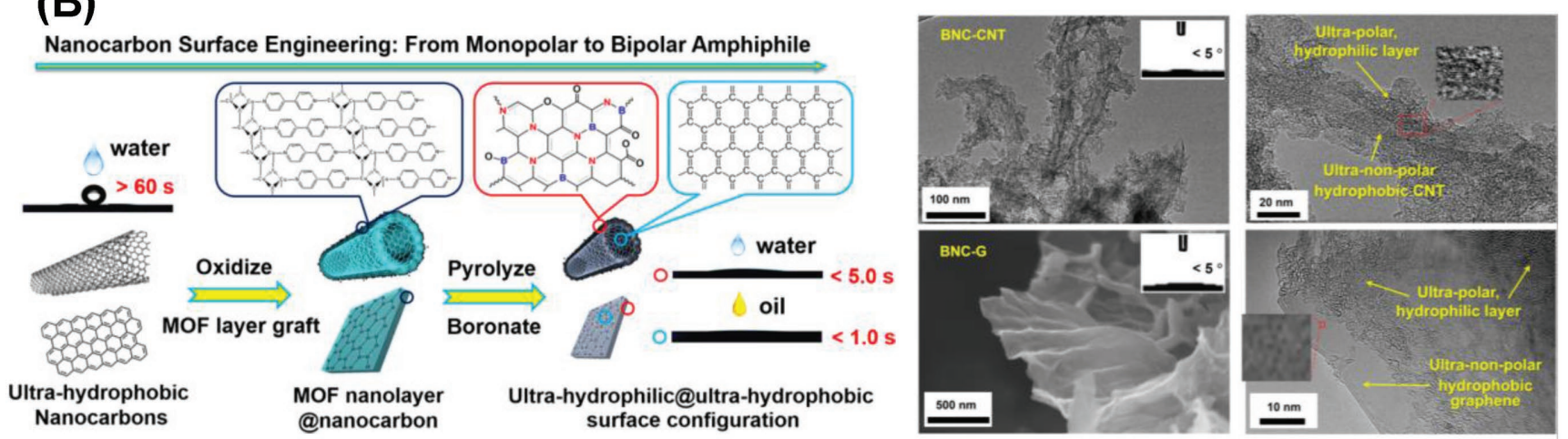

Figure 13. A) FE-SEM and TEM images of the nanozeolite layer deposited by EPD on a current collector (left) and of the ZTC layer obtained from the nanozeolite film after HF washing (scale bars for SEM: $500 \mathrm{~nm}$; inset scale bars: $100 \mathrm{~nm}$ for SEM, $20 \mathrm{~nm}$ for TEM; TEM samples were scratched off the layers before observation). Reproduced with permission. ${ }^{195]}$ Copyright 2013 , the Royal Society of Chemistry. B) Fabrication of bipolar nanocarbon hybrids with hydrophilic@hydrophobic surface configuration as well as TEM images with low and high magnification of a hydrophilic carbon layer on CNT (BNC-CNT, top) and SEM/TEM images of hydrophilic carbon layer on graphene (BNC-G, bottom). Reproduced with permission. [197] Copyright 2016, the American Chemical Society.

to conventional EDLC electrodes, the CDC thin films stand out due to their unique strong interface between active material and current collector (substrate), the elimination of binders, and the absence of macropores between the carbon particles (Figure 12A,B).

More recent examples of formation of thin CDC layers involve the partial chlorination of the external areas of vanadium carbide $^{[190]}$ and titanium carbide ${ }^{[191]}$ particles followed by further chemical conversions to produce $\mathrm{V}_{2} \mathrm{O}_{5} / \mathrm{CDC}$ (Figure 12D) or microporous carbon/graphitic carbon core-shell materials, respectively. Such hierarchical pore systems or hybrid structures can be used in advanced electrochemical energy storage devices and such structures further underline the versatility of this approach for the production of thin microporous carbon layers on multiple substrates.

Another class of microporous carbon materials with welldefined properties are the so-called zeolite-templated carbons (ZTCs). ${ }^{[192]}$ ZTCs are conventionally produced by infiltration of zeolite pore networks with carbon precursors followed by carbonization and template removal. Hence, an ordered microporous carbon negative replica of the zeolite pore system is obtained. ZTCs are characterized by large gravimetric (2000-4000 $\mathrm{m}^{2} \mathrm{~g}^{-1}$ ) and volumetric (1400-1700 $\left.\mathrm{m}^{2} \mathrm{~cm}^{-3}\right)$ surface areas and are promising candidates for both gas adsorption ${ }^{[193]}$ and electrochemical energy storage. ${ }^{[194]}$ Especially in the latter field the low density and small particle size are drawbacks for the process-ability of as-made ZTC powder into electrodes. Electrophoretic deposition of nanozeolite films on porous carbon disks followed by chemical vapor deposition (CVD) in an acetylene stream at $873 \mathrm{~K}$, thermal annealing of the resulting carbon-coated material at $1123 \mathrm{~K}$, and removal of the zeolite template with HF washing is one way for the direct synthesis of binderless ZTC tin film electrodes (Figure 13A). ${ }^{[195]}$ More recently, Rosas et al. used the electro-spraying method to deposit continuous films of ZTC on stainless steel and different carbon substrates together with Nafion as the binder. ${ }^{[196]}$ The "bottom-up character" of this method makes it very versatile in terms of film thickness. Surface loadings between 0.1 and $1.5 \mathrm{mg} \mathrm{cm}{ }^{-2}$ can be achieved and thus films can be tuned for the use in specific applications ranging from electrochemical sensors to energy storage. In both cases, EDLCs based on the ZTC thin films showed superior properties in comparison to the devices based on electrodes obtained by conventional powder processing.

In most cases, thin-film engineering of nanoporous carbon materials follows the aim to deposit a high surface area carbonaceous layer on substrates with different chemical properties. However, thin layers of heteroatom-doped carbon on carbon substrates can also be used to tailor the electronic structure and surface polarity of carbon materials themselves. Such heteroatom-doping of carbons can be crucial in many applications. In one recent example, Hao et al. proposed a surface engineering strategy to modify CNTs and graphene as examples for nonpolar nanocarbons to highly amphiphilic with ultrahydrophilic@ ultrahydrophobic surface properties and a hierarchical pore structure (Figure 13B). ${ }^{[197]}$ A thin layer of metal-organic frameworks grafted on the CNT or graphene surface can serve as precursor for the hydrophilic layer. Additional salt-templating and pyrolysis 

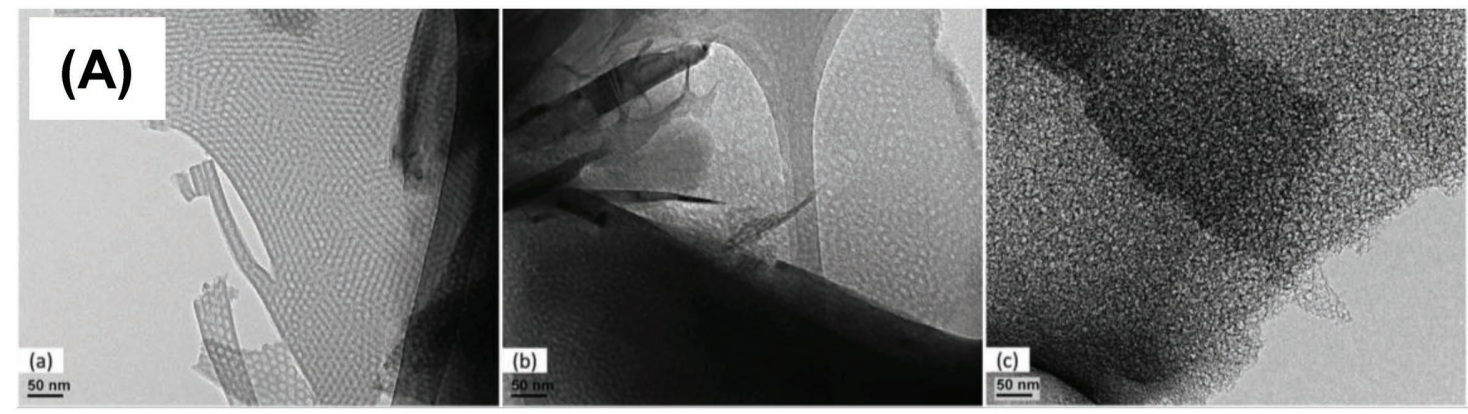

(B)

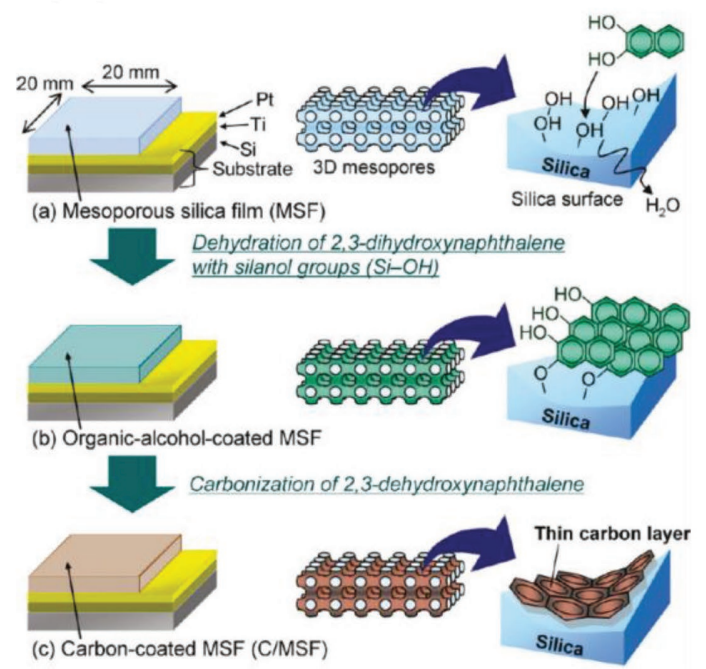

(C)

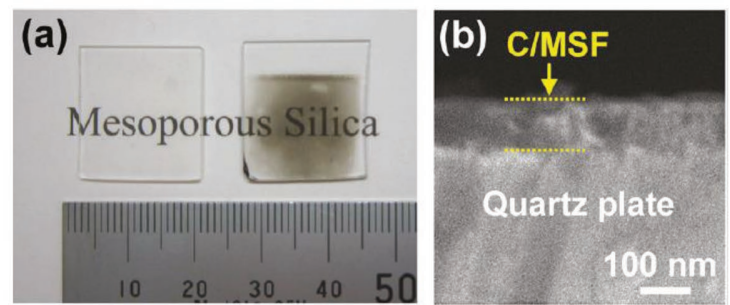

(c)

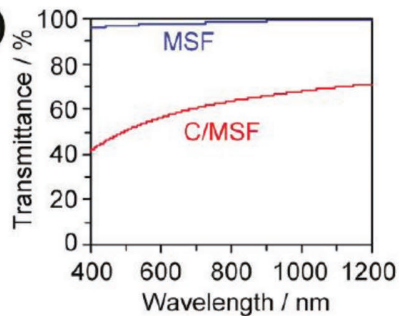

Figure 14. A) TEM images of mesoporous silica thin film (left), composite silica/carbon thin film (middle), and mesoporous carbon thin film (right). Reproduced with permission. ${ }^{[201]}$ Copyright 2016, the Royal Society of Chemistry. B) Preparation procedure of a carbon-coated mesoporous silica film (C/MSF) via alcohol-coating and subsequent carbonization. Reproduced with permission. ${ }^{[204]}$ Copyright 2011 , the American Chemical Society. C) Top, left: Photographs of MSF (left) and C/MSF (right) formed on the quartz plates. One end of each plate was not covered with the mesoporous layer. Top, right: SEM image of the cross-section of C/MSF-Quartz. Bottom: Transmittance of the MSF and C/MSF on the quartz plates at different wavelengths. Reproduced with permission. ${ }^{[204]}$ Copyright 2011, the American Chemical Society.

followed by leaching leads to $10-30 \mathrm{~nm}$ thin highly hydrophilic and porous surface carbon layers with rich surface heterogeneity (boron and nitrogen-doping contents of both up to $\approx 10$ at\%).

Thin Films of Carbons with Ordered Mesopores: Carbon materials with amorphous microstructure but well-ordered pore systems are known for their high surface areas, periodically arranged monodispersed pore space, and tunable pore sizes/pore geometries. Especially ordered mesoporous carbons (OMCs) provide high accessible surface area and advanced materials transport properties leading to outstanding properties in energy and environmentally relevant fields. ${ }^{[198,199]}$ Typically, OMCs are produced by hard or soft-templating approaches.

In hard-templating (also referred to as "nanocasting") a solid ordered mesoporous material (most of the time silica) is used as the template, which is filled with carbon precursor followed by carbonization and template removal. Hence, this concept is comparable to the ZTC synthesis described above. With this strategy, well-defined materials with long-range ordered pore systems of different geometry can be obtained by using different templates, carbon precursors, and infiltration methods. ${ }^{[200]}$ While nanocasting is very versatile in terms of approachable pore structures and material morphologies, thin-film engineering of hard-templated OMCs is rather challenging. As one example, Levi-García et al. reported the synthesis of an ordered mesoporous silica thin film with mesopores of around $8 \mathrm{~nm}$ in size perpendicularly disposed to a graphite substrate followed by nanocasting transformation to an OMC thin film with mesopore sizes in the range of 2-3 nm (Figure 14A). ${ }^{[201]}$ Applications of hard-templated carbon thin films are mainly located in the fields of electrochemical energy storage, ${ }^{[201]}$ electrocatalysis (e.g., in fuel cells) ${ }^{[202]}$ or in gas sensing. ${ }^{[203]}$ Nevertheless, synthesis of binder-free carbon thin films with well-ordered mesopores and high mechanical stability remains complicated with the nanocasting approach. This is most likely due to the fact that template removal is the final step in the synthesis protocol. This leads to lose bounding between the individual carbon particles and between the carbon film and the substrate.

One obvious way to overcome this drawback is the similar use of the template as part of the substrate, that is, to forego the template removal step. Nishihara et al. showed that a $20 \mathrm{~mm} \times 20 \mathrm{~mm}$ large mesoporous silica film of $\sim 200 \mathrm{~nm}$ 
thickness synthesized on different substrates by a vapor infiltration technique can be uniformly coated with a nm-thin continuous carbon layer by using 2,3-dihydroxynaphthalene as the carbon precursor (Figure 14B). ${ }^{[204]}$ The resulting carbon/ silica material has small mesopores of $\sim 2 \mathrm{~nm}$ in size and is more promising as electrode materials in EDLCs as compared to conventional powdered electrodes. This is assigned to the continuous and uniform character of the carbon layer leading to high conductivity of the electrodes. The carbon-coated mesoporous silica film further shows high light transmittance (67.9\% at a wavelength of $1000 \mathrm{~nm}$ ) if a quartz substrate is used (Figure 14C) and could thus be utilized as transparent conductive electrode. Just like in regular ("bulk") nanocasting the pore structure of such carbon nanolayers can be controlled by the pore structure of the silica support. ${ }^{[205,206]}$

Besides ordered mesoporous silica materials, anodic aluminum oxide (AAO) is another useful hard template for the synthesis of nanostructured carbon thin films. AAO consists of an array of cylindrical pores with diameters from 20-200 nm and lengths of 0.1-70 $\mu \mathrm{m} .{ }^{[207]}$ With such a template, self-standing arrays of carbon nanotubes (surface coating of the alumina pores) or nanorods (complete filling of the alumina pores) on a carbon substrate can be synthesized by forming an "anchoring" carbon layer on one side of the AAO. Methods for the carbon filling of the AAO pore space include CVD ${ }^{[208]}$ or impregnation techniques ${ }^{[209]}$ followed by subsequent carbonization. Removal of the AAO template is usually achieved by dissolution in an alkaline media such as $\mathrm{NaOH}$ solution. With this method, the porosity of the obtained carbon film can be precisely adjusted and heteroatoms (e.g., nitrogen or boron) can also be introduced into the carbon framework. ${ }^{[210]}$ Furthermore, the carbon films offer a high pore volume to host functional guest species. For example, composites of AAO-templated thin films with nickel and manganese oxide have been applied as electrocatalysts ${ }^{[211]}$ or as cathode materials in lithium batteries, ${ }^{[212]}$ respectively.

In soft-templating, which has been pioneered by Dai, ${ }^{[213]}$ Nishiyama, ${ }^{[214]}$ and Zhao ${ }^{[215]}$ together with their co-workers, OMCs are directly synthesized by molecular self-assembly of a carbon precursor (often phenolic resin) and a structuredirecting agent (usually a block-copolymer is used as surfactant) followed by the formation of a mesoporous polymer during surfactant removal and final carbonization. ${ }^{[216,217]}$ Hence, fewer synthesis steps and no hard templates are needed in this direct soft-templating approach (Figure 15A). The pore structure of the soft-templated OMCs can be adjusted by the size and structure of the supramolecular aggregates, temperature, type of solvent, and ionic strength. ${ }^{[217]}$

In terms of thin-film production, one obvious advantage of the soft-templating method (compared to nanocasting) is that the carbon materials can be directly produced as films. The most common method for the assembly between structuredirecting surfactants and carbon precursors is the so-called evaporation induced self-assembly (EISA) method. EISA is usually performed on different substrates and thus the assembled materials can be further processed to carbon materials while keeping their thin-film morphology. For example, Zhao and co-workers reported the synthesis of free-standing mesoporous carbon films with a thickness of $90 \mathrm{~nm}$ up to $3 \mu \mathrm{m}$ by a coating-etching approach on a pre-oxidized silicon wafer as the substrate. ${ }^{[218]}$ After carbonization, the carbon films are free-standing and have a crack-free uniform morphology. After removal of the oxide layer of the substrate, they can be transferred or bent on different surfaces. Mesopore sizes and mesostructures can be controlled by the template or by the composition of the template/carbon precursor mixture rendering soft-templating a highly versatile method for synthesis of carbon thin films with a wide range of properties. Furthermore, the same group has shown that ordered mesoporous silica/ carbon composite films can be synthesized by spin coating of a mixture of triblock copolymer Pluronic F127 (surfactant), resin (carbon precursor) and tetraethoxylsilane (silica precursor) on $\mathrm{Al}_{2} \mathrm{O}_{3}$-coated $\mathrm{Si}$ substrates (Figure 15B,C). ${ }^{[219]}$ After carbonization and removal of the substrate as well as the silica part of the composite (acting as secondary hard template), free-standing carbon films with significantly enhanced specific surface areas exceeding $2000 \mathrm{~m}^{2} \mathrm{~g}^{-1}$ are obtained. The silica acts as additional hard template creating pores within the mesopore walls upon its removal, leading to an approximately four times increase of the surface area as compared to the parent carbon-silica composite thin film and an approximately three times increase as compared to the carbon film without silica hard template reported earlier. ${ }^{[218]}$ Alternatively, the carbon part of the composite can also be removed by calcination and highly porous free-standing silica films can be obtained.

The mesopore architecture can also be influenced by double solvent vapor annealing and post thermal annealing process that induces an order-order transition from parallel cylinder arrangements to a gyroid structure as reported by Vogt and coworkers (Figure 15D). ${ }^{[220]}$ Another important aspect is that thin films of soft-templated OMCs can be synthesized on nanostructured substrates. For example, Lee et al. synthesized OMCs films with different pore structures on Nickel nanofoams as current collectors in order to obtain binder-free EDLC electrodes with plentiful surface area and significantly shortened electronic/ionic current paths. ${ }^{\text {[221] }}$

The EISA method can further be combined with the CDC approach by the synthesis of free-standing films of ordered mesoporous silicon carbide-carbon and titanium carbidecarbon composites by soft templating followed by high-temperature chlorine treatment. ${ }^{[22]}$ The hierarchical micro/mesopore architecture in the films leads to high specific surface area and total pore volume of $1538 \mathrm{~m}^{2} \mathrm{~g}^{-1}$ and $2.53 \mathrm{~cm}^{3} \mathrm{~g}^{-1}$, respectively.

In contrast to the hard-templated carbon thin films, which are so far mainly used in EDLCs, there seem to be many more fields of application for soft-templated ordered mesoporous carbon films including adsorption processes ${ }^{[223]}$ or drug delivery ${ }^{[224]}$ to mention two examples. Furthermore, the welldefined porosity and high mechanical integrity of such films makes them attractive as hosts for metal or metal oxide guest species. Such metal(oxide) carbon composites are then attractive, e.g., for electrochemical energy storage in pseudocapacitors, ${ }^{[225]}$ or for applications in catalysis. ${ }^{[226]}$

\section{Summary and Outlook}

The field of porous organic and carbon-based thin films is at an exciting stage due to the diverse nature of the different 
(A)

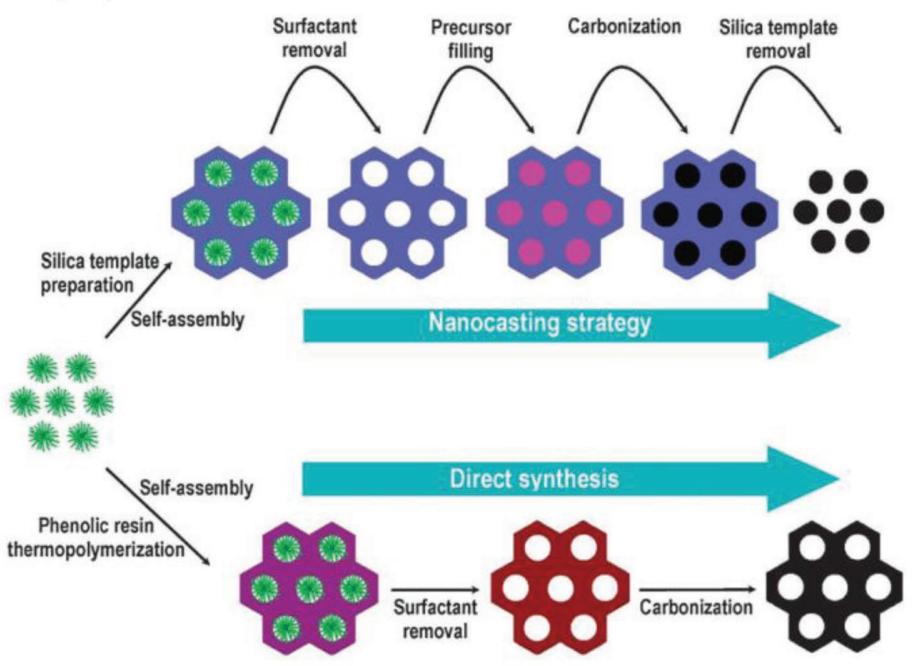

(C)

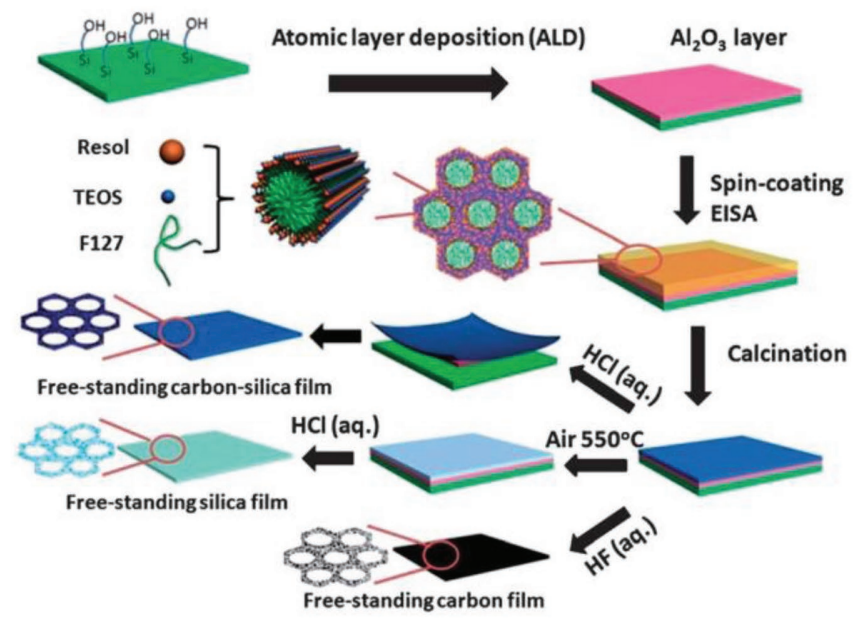

(B)
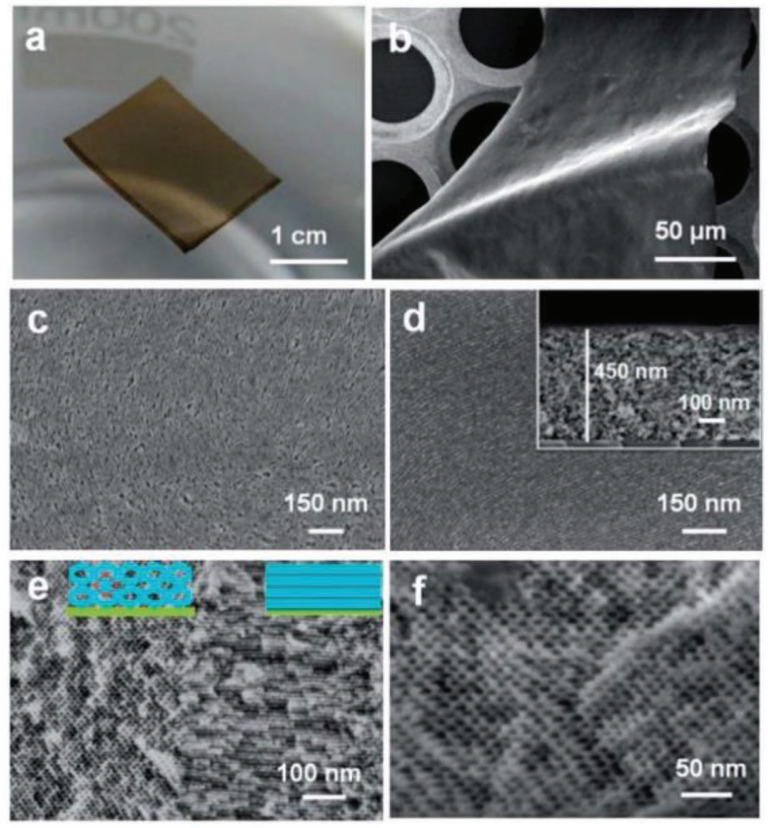

(D)

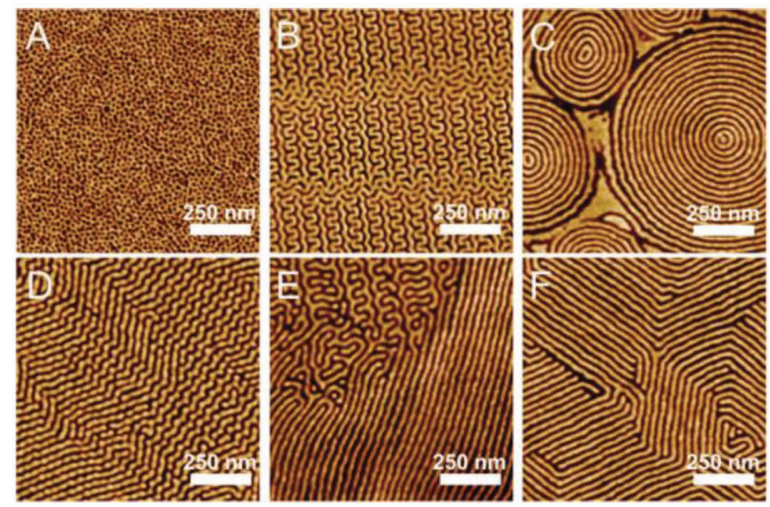

Figure 15. A) Comparison of the synthesis of OMCs by the nanocasting strategy from mesoporous silica hard templates and the direct synthesis from block copolymer soft templates. Reproduced with permission. ${ }^{[217]}$ Copyright 2013, the Royal Society of Chemistry. B-a) Photo of a free-standing mesoporous carbon-silica composite thin film floating on water and C-b-f) SEM images of the mesoporous carbon-silica composite thin films: b) lowmagnification; c) the top surface, and d) the bottom surface. The inset in (d) is the cross-sectional SEM image showing the thickness of the film; $\mathrm{e}, \mathrm{f}$ ) cross-sectional images. The inset in (e) shows structural models of the mesochannel orientation. C) Synthesis process for free-standing mesoporous carbon-silica composite thin films, silica films, and carbon films by using a coating-etching approach $(B, C)$ reproduced with permission. ${ }^{[219]}$ Copyright 2013, the Royal Society of Chemistry. D) AFM phase images of carbon thin films produced with different amounts of resolution after exposure to methyl ethyl ketone using a single solvent vapor annealing process. Reproduced with permission. ${ }^{[220]}$ Copyright 2014, the Royal Society of Chemistry.

material classes, combined with novel processing techniques to generate thin films on various substrates or even freestanding membranes, paving the way toward their integration into functional devices. The knowledge and understanding of this diversity in terms of the naturally inherent material chemistry and properties as well as available processing techniques allows to select the best material for a specific purpose. Comparing the different material classes, key advantage such as the enormous synthetic versatility in POPs, the long range order in COFs, the intrinsic solution processability in POCs or the extreme thermal stability in porous carbons are only rough guidelines in the choice of the right material, since each class of materials comes with its own diversity in terms of stability, functionalization, and processing.

Despite the different procedures for their (bulk) synthesis, all these materials face similar challenges when prepared them as thin films, namely the formation of homogeneous and pinhole free coatings of controlled and uniform thickness. However, the common feature-porosity-adds an additional challenge, the preserved accessibility of active or functional sites throughout the entire film. To overcome this challenge, carefully controlled deposition conditions or post synthetic 
activation procedures were developed to ensure high porosity in the final thin films.

An additional important aspect for the field of porous organic and carbon-based thin films is the need for better characterization techniques. Especially more sensitive and readily available techniques are required for thin films with thicknesses below $50 \mathrm{~nm}$, as classical characterization techniques fail to determine porosity or crystallinity due to low sample amounts.

A general challenge toward application and commercialization of these materials is to scale-up especially in regards with environmentally friendly production as well as their long term stability. In addition, when aiming for a specific application one needs to consider the classical production techniques, since the barrier for its application will be significantly reduced when the novel material can be integrated within the established thin-film production techniques. Therefore, established thinfilm production techniques such as spin coating or vapor-phase deposition are preferred and should be the first choice when synthesizing thin films of novel materials.

With all these observations and the points outlined in this review, the central mission for the future will be to control porous thin films, both on macroscopic and molecular levels, for optimizing their performance. We anticipate a bright and promising future for organic and carbon-based porous thin films, with their utility as a powerful platform to achieve challenging environmental and energy related goals.

\section{Acknowledgements}

The authors greatly acknowledge the German Research Foundation, Deutsche Forschungs Gemeinschaft (DFG), Sondern Forschung Bereich (SFB 1176, C5) and the Helmholtz Association Young Investigator Program (M.T) at Karlsruhe Institute of Technology for their financial support.
[6] Z. Li, J.C. Barnes, A. Bosoy, J. F. Stoddart, J. I. Zink, Chem. Soc. Rev. 2012, 41, 2590

[7] H. Furukawa, K.E. Cordova, M. O'Keeffe, O.M. Yaghi, Science 2013, 34, 1230444.

[8] M. Peplow, Nature 2015, 520, 148.

[9] S. Horike, S. Shimomura, S. Kitagawa, Nat. Chem. 2009, 1, 695.

[10] S. Wuttke, M. Lismont, A. Escudero, B. Rungtaweevoranit, W. J. Parak, Biomaterials 2017, 123, 172.

[11] M. Limont, L. Dreesen, S. Wuttke, Adv. Funct. Mater. 2017, 27, 1606314.

[12] R. Freund, U. Lächelt, T. Gruber, B. Rühle, S. Wuttke, ACS Nano 2018, 12, 2094.

[13] M. Peller, K. Böll, A. Zimpel, S. Wuttke, Inorg. Chem. Front. 2018, https://doi.org/10.1039/C8QI00149A.

[14] K. Adil, Y. Belmabkhout, R. S. Pillai, A. Cadiau, P. M. Bhatt, A. H. Assen, G. Maurin, M. Eddaoudi, Chem. Soc. Rev. 2017, 46, 3402.

[15] W. P. Lustig, S. Mukherjee, N. D. Rudd, A. V. Desai, J. Li, S. K. Ghosh, Chem. Soc. Rev. 2017, 46, 3242.

[16] I. Stassen, N. Burtch, A. Talin, P. Falcaro, M. Allendorf, R. Ameloot, Chem. Soc. Rev. 2017, 46, 3185.

[17] N. S. Bobbitt, M. L. Mendonca, A. J. Howarth, T. Islamoglu, Joseph T. Hupp, O. K. Farha, R. Q. Snurr, Chem. Soc. Rev. 2017, 46, 3357.

[18] S. M. J. Rogge, A. Bavykina, J. Hajek, H. Garcia, A. I. Olivos-Suarez, A. Sepúlveda-Escribano, A. Vimont, G. Clet, P. Bazin, F. Kapteijn, M. Daturi, E. V. Ramos-Fernandez, F. X. L. i Xamena, V. Van Spey broeck, J. Gascon, Chem. Soc. Rev. 2017, 46, 3134.

[19] P. Z. Moghadam, A. Li, S. B. Wiggin, A. Tao, A. G. P. Maloney, P. A. Wood, S. C. Ward, D. F. Jimenez, Chem. Mater. 2017, 29, 2618.

[20] P. Innocenzi, L. Malfattia, Chem. Soc. Rev. 2013, 42, 4198.

[21] C. Sanchez, C. Boissière, D. Grosso, C. Laberty, L. Nicole, Chem. Mater. 2008, 20, 682.

[22] N. Chaoui, M. Trunk, R. Dawson, J. Schmidt, A. Thomas, Chem. Soc. Rev. 2017, 46, 3302.

[23] http://www.3m.com/ServiceLifelndicator.

[24] a) Q. Chen, D.-P. Liu, M. Luo, L.-J. Feng, Y.-C. Zhao, B.-H. Han, Small 2014, 10, 308; b) Q. Chen, D.-P. Liu, J.-H. Zhu, B.-H. Han, Macromolecules 2014, 47, 5926; c) Q. Chen, M. Luo, P. Hammershøj, D. Zhou, Y. Han, B. W. Laursen, C.-G. Yan, B.-H. Han, J. Am. Chem. Soc. 2012, 134, 6084; d) A. K. Sekizkardes, S. Altarawneh, Z. Kahveci, T. İslamoğlu, H. M. El-Kaderi, Macromolecules 2014, 47, 8328; e) A. K. Sekizkardes, J. T. Culp, T. Islamoglu, A. Marti, D. Hopkinson, C. Myers, H. M. El-Kaderi, H. B. Nulwala, Chem. Commun. 2015, 51, 13393.

[25] a) Y. Zhang, S. A, Y. Zou, X. Luo, Z. Li, H. Xia, X. Liu, Y. Mu, J. Mater. Chem. A 2014, 2, 13422; b) M. Rose, ChemCatChem 2014, 6, 1166; c) C. Bleschke, J. Schmidt, D. S. Kundu, S. Blechert, A. Thomas, Adv. Synth. Catal. 2011, 353, 3101.

[26] X. Liu, Y. Xu, D. Jiang, J. Am. Chem. Soc. 2012, 134, 8738.

[27] J. L. Novotney, W. R. Dichtel, ACS Macro Lett. 2013, 2, 423.

[28] X.-M. Hu, Q. Chen, D. Zhou, J. Cao, Y.-J. He, B.-H. Han, Polym. Chem. 2011, 2, 1124.

[29] E. Özdemir, D. Thirion, C. T. Yavuz, RSC Adv. 2015, 5, 69010.

[30] L.-M. Tao, F. Niu, D. Zhang, T.-M. Wang, Q.-H. Wang, New J. Chem. 2014, 38, 2774.

[31] Y. Zhang, A. Sigen, Y. Zou, X. Luo, Z. Li, H. Xia, X. Liu, Y. Mu, J. Mater. Chem. A 2014, 2, 13422.

[32] A. R̈aupke, A. Palma-Cando, E. Shkura, P. Teckhausen, A. Polywka, P. Görrn, U. Scherf, T. Riedl, Sci. Rep. 2016, 6, 29118.

[33] G. Zhang, Z.-A. Lan, X. Wang, Angew. Chem., Int. Ed. 2016, 55, 15712.

[34] D. Wu, F. Xu, B. Sun, R. Fu, H. He, K. Matyjaszewski, Chem. Rev. 2012, 112, 3959.

[35] Y. Zhang, S. N. Riduan, Chem. Soc. Rev. 2012, 41, 2083. 
[36] Y. Xu, S. Jin, H. Xu, A. Nagai, D. Jiang, Chem. Soc. Rev. 2013, 42, 8012.

[37] K. E. Maly, J. Mater. Chem. 2009, 19, 1781.

[38] P. Kaur, J. T. Hupp, S. T. Nguyen, ACS Catal. 2011, 1, 819.

[39] A. I. Cooper, Adv. Mater. 2009, 21, 1291.

[40] J.-X. Jiang, A. I. Cooper, Top. Curr. Chem. 2009, 293, 1.

[41] Z. Chang, D. S. Zhang, Q. Chen, X. H. Bu, Phys. Chem. Chem. Phys. 2013, 15, 5430.

[42] Y. L. Wong, J. M. Tobin, Z. Xu, F. Vilela, J. Mater. Chem. A 2016, 48, 18677.

[43] C. Coperet, A. Comas-Vives, M. P. Conley, D. P. Estes, A. Fedorov, V. Mougel, H. Nagae, F. Nunez-Zarur, P. A. Zhizhko, Chem. Rev. 2016, 116, 323.

[44] W. Zhang, B. Aguila, S. Ma, J. Mater. Chem. A 2017, 5, 8795.

[45] H. Bildirir, V. G. Gregoriou, A. Avgeropoulos, U. Scherf, C. L. Chochos, Mater. Horiz. 2017, 4, 546.

[46] Handbook of Zeolite Science and Technology (Eds: S. M. Auerbach, K. A. Carrado, P. K. Dutta, M. Dekker), Taylor and Francis, New York 2003, https://books.google.be/books/about/Handbook_of_Zeolite_ Science_and_Technolo.html?id=VOHkngEACAAJ\&redir_esc $=y$.

[47] S. I. Swamy, J. Bacsa, J. T. A. Jones, K. C. Stylianou, A. Steiner, L. K. Ritchie, T. Hasell, J. A. Gould, A. Laybourn, Y. Z. Khimyak, D. J. Adams, M. J. Rosseinsky, A. I. Cooper, J. Am. Chem. Soc. 2010, 132, 12773.

[48] J. Dechnik, J. Gascon, C. J. Doonan, C. Janiak, C. J. Sumby, Angew. Chem., Int. Ed. 2017, 56, 9292.

[49] N. B. McKeown, J. Mater. Chem. 2010, 20, 10588.

[50] N. B. McKeown, P. M. Budd, Macromolecules 2010, 43, 5163.

[51] T. Hasell, A. I. Cooper, Nat. Rev. Mater. 2016, 1, 1.

[52] J. R. Holst, A. Trewin, A. I. Cooper, Nat. Chem. 2010, 2, 915.

[53] L. J. Barbour, Chem. Commun. 2006, 1163.

[54] P. Sozzani, S. Bracco, A. Comotti, L. Ferretti, R. Simonutti, Angew. Chem., Int. Ed. 2005, 44, 1816.

[55] A. Cruz-Cabeza, G. Day, W. Jones, Chem. - Eur. J. 2009, 15, 13033.

[56] J. Tian, P. K. Thallapally, B. P. McGrail, CrystEngComm 2012, 14, 1909.

[57] Y.-F. Han, Y.-X. Yuan, H.-B. Wang, Molecules 2017, 22, 266.

[58] M. Mastalerz, I. M. Oppel, Angew. Chem., Int. Ed. 2012, 51, 5252.

[59] W. Yang, A. Greenaway, X. Lin, R. Matsuda, A. J. Blake, C. Wilson, W. Lewis, P. Hubberstey, S. Kitagawa, N. R. Champness, M. Schröder, J. Am. Chem. Soc. 2010, 132, 14457.

[60] M. M. Green, N. C. Peterson, T. Sato, A. Teramoto, R. Cook, S. Lifson, Science 1995, 268, 1860.

[61] Y. Fang, E. Ghijsens, O. Ivasenko, H. Cao, A. Noguchi, K. S. Mali, K. Tahara, Y. Tobe, S. De Feyter, Nat. Chem. 2016, 8, 711

[62] J. A. Theobald, N. S. Oxtoby, M. A. Phillips, N. R. Champness, P. H. Beton, Nature 2003, 424, 1029.

[63] Y. Jiao, F. H. Stillinger, S. Torquato, Phys. Rev. Lett. 2008, 100, 245504.

[64] Y. Jiao, F. H. Stillinger, S. Torquato, Phys. Rev. E 2009, 79, 041309.

[65] P. M. Budd, B. S. Ghanem, S. Makhseed, N. B. McKeown, K. J. Msayib, C. E. Tattershall, Chem. Commun. 2004, 0, 230.

[66] R. G. D. Taylor, C. G. Bezzu, M. Carta, K. J. Msayib, J. Walker, R. Short, B. M. Kariuki, N. B. McKeown, Chem. - Eur.J. 2016, 22, 2466.

[67] B. Kohl, F. Rominger, M. Mastalerz, Org. Lett. 2014, 16, 704.

[68] B. Kohl, F. Rominger, M. Mastalerz, Chem. - Eur. J. 2015, 21, 17308.

[69] G. Zhang, M. Mastalerz, Chem. Soc. Rev. 2014, 43, 1934.

[70] G. Zhang, O. Presly, F. White, I. M. Oppel, M. Mastalerz, Angew. Chem., Int. Ed. 2014, 53, 1516

[71] M. E. Briggs, A. I. Cooper, Chem. Mater. 2017, 29, 149.

[72] D. P. Lydon, N. L. Campbell, D. J. Adams, A. I. Cooper, Synth. Commun. 2011, 41, 2146.

[73] T. Tozawa, J. T. A. Jones, S. I. Swamy, S. Jiang, D. J. Adams, S. Shakespeare, R. Clowes, D. Bradshaw, T. Hasell, S. Y. Chong, C. Tang, S. Thompson, J. Parker, A. Trewin, J. Bacsa, A. M. Z. Slawin, A. Steiner, A. I. Cooper, Nat. Mater. 2009, 8, 973.
[74] M. Mastalerz, M. W. Schneider, I. M. Oppel, O. Presly, Angew. Chem., Int. Ed. 2011, 50, 1046.

[75] M. W. Schneider, I. M. Oppel, H. Ott, L. G. Lechner, H.-J. S. Hauswald, R. Stoll, M. Mastalerz, Chem. - Eur. J. 2012, 18, 836.

[76] M. Liu, M. A. Little, K. E. Jelfs, J. T. A. Jones, M. Schmidtmann, S. Y. Chong, T. Hasell, A. I. Cooper, J. Am. Chem. Soc. 2014, 136, 7583.

[77] S. Bera, A. Basu, S. Tothadi, B. Garai, S. Banerjee, K. Vanka, R. Banerjee, Angew. Chem., Int. Ed. 2017, 56, 2123.

[78] A. Avellaneda, P. Valente, A. Burgun, J. D. Evans, A. W. MarkwellHeys, D. Rankine, D. J. Nielsen, M. R. Hill, C. J. Sumby, C. J. Doonan, Angew. Chem., Int. Ed. 2013, 52, 3746.

[79] M. E. Briggs, A. G. Slater, N. Lunt, S. Jiang, M. A. Little, R. L. Greenaway, T. Hasell, C. Battilocchio, S. V. Ley, A. I. Cooper, Chem. Commun. 2015, 51, 17390.

[80] M. Kitchin, K. Konstas, C. J. Sumby, M. L. Czyz, P. Valente, M. R. Hill, A. Polyzos, C. J. Doonan, Chem. Commun. 2015, 51, 14231.

[81] S. Lee, A. Yang, T. P. Moneypenny, J. S. Moore, J. Am. Chem. Soc. 2016, 138, 2182

[82] T. Hasell, S. Y. Chong, K. E. Jelfs, D. J. Adams, A. I. Cooper, J. Am. Chem. Soc. 2012, 134, 588.

[83] S. Jiang, J. T. A. Jones, T. Hasell, C. E. Blythe, D. J. Adams, A. Trewin, A. I. Cooper, Nat. Commun. 2011, 2, 207.

[84] T. Hasell, J. L. Culshaw, S. Y. Chong, M. Schmidtmann, M. A. Little, K. E. Jelfs, E. O. Pyzer-Knapp, H. Shepherd, D. J. Adams, G. M. Day, A. I. Cooper, J. Am. Chem. Soc. 2014, 136, 1438.

[85] M. A. Little, S. Y. Chong, M. Schmidtmann, T. Hasell, A. I. Cooper, Chem. Commun. 2014, 50, 9465.

[86] J. T. A. Jones, T. Hasell, X. Wu, J. Bacsa, K. E. Jelfs, M. Schmidtmann, S. Y. Chong, D. J. Adams, A. Trewin, F. Schiffman, F. Cora, B. Slater, A. Steiner, G. M. Day, A. I. Cooper, Nature 2011, 474, 367.

[87] T. Hasell, S. Y. Chong, M. Schmidtmann, D. J. Adams, A. I. Cooper, Angew. Chem., Int. Ed. 2012, 51, 7154.

[88] M. A. Little, M. E. Briggs, J. T. A. Jones, M. Schmidtmann, T. Hasell, S. Y. Chong, K. E. Jelfs, L. Chen, A. I. Cooper, Nat. Chem. 2015, 7, 153.

[89] Q. Song, S. Jiang, T. Hasell, M. Liu, S. Sun, A. K. Cheetham, E. Sivaniah, A. I. Cooper, Adv. Mater. 2016, 28, 2629.

[90] M. Brutschy, M. W. Schneider, M. Mastalerz, S. R. Waldvogel, Adv. Mater. 2012, 24, 6049.

[91] M. Brutschy, M. W. Schneider, M. Mastalerz, S. R. Waldvogel, Chem. Commun. 2013, 49, 8398.

[92] T. Hasell, M. Schmidtmann, A. I. Cooper, J. Am. Chem. Soc. 2011, $133,14920$.

[93] M. Liu, L. Chen, S. Lewis, S. Y. Chong, M. A. Little, T. Hasell, I. M. Aldous, C. M. Brown, M. W. Smith, C. A. Morrison, L. J. Hardwick, A. I. Cooper, Nat. Commun. 2016, 7, 12750.

[94] M. Mastalerz, Chem. Commun. 2008, 4756.

[95] S. Jiang, Q. Song, A. Massey, S. Y. Chong, L. Chen, S. Sun, T. Hasell, R. Raval, E. Sivaniah, A. K. Cheetham, A. I. Cooper, Angew. Chem., Int. Ed. 2017, 56, 9391.

[96] K. Norrman, A. Ghanbari-Siahkali, N. B. Larsen, Annu. Rep. Prog. Chem., Sect. C: Phys. Chem. 2005, 101, 174.

[97] O. Shekhah, J. Liu, R. A. Fischer, C. Wöll, Chem. Soc. Rev. 2011, 40, 1081.

[98] J. T. A. Jones, D. Holden, T. Mitra, T. Hasell, D. J. Adams, K. E. Jelfs, A. Trewin, D. J. Willock, G. M. Day, J. Bacsa, A. Steiner, A. I. Cooper, Angew. Chem., Int. Ed. 2011, 50, 749.

[99] R. Dawson, A. I. Cooper, D. J. Adams, Prog. Polym. Sci. 2012, 37, 530.

[100] J.-X. Jiang, F. Su, A. Trewin, C. D. Wood, N. L. Campbell, H. Niu, C. Dickinson, A. Y. Ganin, M. J. Rosseinsky, Y. Z. Khimyak, A. I. Cooper, Angew. Chem., Int. Ed. 2007, 46, 8574.

[101] J.-X. Jiang, F. Su, A. Trewin, C. D. Wood, H. Niu, J. T. A. Jones, Y. Z. Khimyak, A. I. Cooper, J. Am. Chem. Soc. 2008, 130, 7710. 
[102] T. Ben, H. Ren, S. Ma, D. Cao, J. Lan, X. Jing, W. Wang, J. Xu, F. Deng, J. M. Simmons, S. Qiu, G. Zhu, Angew. Chem., Int. Ed. 2009, 48, 9457.

[103] D. Yuan, W. Lu, D. Zhao, H.-C. Zhou, Adv. Mater. 2011, 23, 3723.

[104] H. Furukawa, K. E. Cordova, M. O'Keeffe, O. M. Yaghi, Science 2013, 341.

[105] A. G. Slater, A. I. Cooper, Science 2015, 348.

[106] N. B. McKeown, P. M. Budd, Chem. Soc. Rev. 2006, 35, 675.

[107] N. B. McKeown, P. M. Budd, K. J. Msayib, B. S. Ghanem, H. J. Kingston, C. E. Tattershall, S. Makhseed, K. J. Reynolds, D. Fritsch, Chem. - Eur. J. 2005, 11, 2610.

[108] G. P. Robertson, J. Song, I. Pinnau, M. D. Guiver, Macromoleculs 2009, 42, 6038.

[109] H. B. Park, G. P. Robertson, M. M. Dal-Cin, T. Visser, L. Scoles, Nat. Mater. 2011, 10, 372.

[110] M. M. Dal-Cin, A. Nicaleck, G. P. Robertson, I. Pinnau, M. D. Guiver, Macromol. Rapid Commun. 2011, 32, 631.

[111] B. S. Ghanem, N. B. McKeown, P. M. Budd, N. M. Al-Harbi, D. Fritsch, K. Heinrich, Macromol. 2009, 42, 7881.

[112] P. M. Budd, E. S. Elabas, B. S. Ghanem, S. Makhseed, N. B. McKeown, K. J. Msayib, C. E. Tattershall, D. Wang, Adv. Mater. 2004, 16, 456.

[113] D. Becker, N. Konnertz, M. Böhning, J. Schmidt, A. Thomas, Chem. Mater. 2016, 28, 8523.

[114] G. Cheng, T. Hasell, A. Trewin, D. J. Adams, A. I. Cooper, Angew. Chem., Int. Ed. 2012, 51, 12727.

[115] H. Bildirir, V. G. Gregoriou, A. Avgeropoulos, U. Scherf, C. L. Chochos, Mater. Horiz. 2017, 4, 546.

[116] S.-Y. Moon, J.-S. Bae, E. Jeon, J.-W. Park, Angew. Chem., Int. Ed. 2010, 49, 9504

[117] X. Zhu, C. Tian, S. M. Mahurin, S.-H. Chai, C. Wang, S. Brown, G. M. Veith, H. Luo, H. Liu, S. Dai, J. Am. Chem. Soc. 2012, 134, 10478.

[118] P. Kuhn, M. Antonietti, A. Thomas, Angew. Chem., Int. Ed. 2008, 47, 3450.

[119] Y. Yang, Q. Zhang, J. Zheng, S. Zhang, Polymer 2013, 54, 3254.

[120] X. Wu, H. Li, Y. Xu, B. Xu, H. Tong, L. Wang, Nanoscale 2014, 6, 2375.

[121] A. Patra, J.-M. Koenen, U. Scherf, Chem. Commun. 2011, 47, 9612.

[122] D. Becker, N. Heidary, M. Horch, U. Gernert, I. Zebger, J. Schmidt, A. Fischer, A. Thomas, Chem. Commun. 2015, 51, 4283.

[123] V. Senkovskyy, I. Senkovska, A. Kiriy, ACS Macro Lett. 2012, 1, 494.

[124] P. Lindemann, M. Tsotsalas, S. Shishatskiy, V. Abetz, P. Krolla-Sidenstein, C. Azucena, L. Monnereau, A. Beyer, A. Gölzhäuser, V. Mugnaini, H. Gliemann, S. Bräse, C. Wöll Chem. Mater. 2014, 26, 7189.

[125] Q. An, Y. Hassan, X. Yan, P. Krolla-Sidenstein, T. Mohammed, M. Lang, S. Bräse, M. Tsotsalas, Beilstein J. Org. Chem. 2017, 13, 558.

[126] P. Lindemann, A. Schade, L. Monnereau, W. Feng, K. Batra, H. Gliemann, P. Levkin, S. Brase, C. Woll, M. Tsotsalas, J. Mater. Chem. A 2016, 4, 6815.

[127] P. Lindemann, Y. Träutlein, C. Wöll, M. Tsotsalas, J. Visualized Exp. 2015, 106, e53324.

[128] C. Gu, Y. Chen, Z. Zhang, S. Xue, S. Sun, K. Zhang, C. Zhong, H. Zhang, Y. Pan, Y. Lv, Y. Yang, F. Li, S. Zhang, F. Huang, Y. Ma, Adv. Mater. 2013, 25, 3443.

[129] a) A. Palma-Cando, U. Scherf, Macromol. Chem. Phys. 2016, 217, 827; b) A. Yassin, R. Mallet, P. Leriche, J. Roncali, ChemElectroChem 2014, 1, 1219; c) C. Gu, N. Huang, J. Gao, F. Xu, Y. Xu D. Jiang, Angew. Chem., Int. Ed. 2014, 53, 4850.

[130] C. Gu, N. Huang, Y. Chen, L. Qin, H. Xu, S. Zhang, F. Li, Y. Ma, D. Jiang, Angew. Chem., Int. Ed. 2015, 54, 13594.

[131] C. Gu, N. Huang, Y. Wu, H. Xu, D. Jiang, Angew. Chem., Int. Ed. 2015, 54, 11540 .

[132] H. Ma, F. Li, P. Li, H. Wang, M. Zhang, G. Zhang, M. Baumgarten, K. Müllen, Adv. Funct. Mater. 2016, 26, 2025.

[133] H. Zhang, Y. Zhang, C. Gu, Y. Ma, Adv. Energy Mater. 2015, 5, 1402175. [134] N. Huang, P. Wang, D. Jiang, Nat. Rev. Mater. 2016, 1, 16068.
[135] D. D. Medina, T. Sick, T. Bein, Adv. Energy Mater. 2017, 7, 1700387.

[136] P. J. Waller, F. Gándara, O. M. Yaghi, Acc. Chem. Res. 2015, 48, 3053.

[137] C. S. Diercks, O. M. Yaghi, Science 2017, 355.

[138] L. M. Salonen, D. D. Medina, E. Carbo-Argibay, M. G. Goesten, L. Mafra, N. Guldris, J. M. Rotter, D. G. Stroppa, C. Rodriguez-Abreu, Chem. Commun. 2016, 52, 7986.

[139] D. D. Medina, V. Werner, F. Auras, R. Tautz, M. Dogru, J. Schuster, S. Linke, M. Döblinger, J. Feldmann, P. Knochel, T. Bein, ACS Nano 2014, 8, 4042.

[140] J. W. Colson, A. R. Woll, A. Mukherjee, M. P. Levendorf, E. L. Spitler, V. B. Shields, M. G. Spencer, J. Park, W. R. Dichtel, Science 2011, 332, 228.

[141] H. Wang, B. He, F. Liu, C. Stevens, M. A. Brady, S. Cai, C. Wang, T. P. Russell, T. W. Tan, Y. Liu, J. Mater. Chem. C 2017, 5, 5090.

[142] M. Dogru, M. Handloser, F. Auras, T. Kunz, D. Medina, A. Hartschuh, P. Knochel, T. Bein, Angew. Chem., Int. Ed. 2013, 52, 2920.

[143] M. Calik, F. Auras, L. M. Salonen, K. Bader, I. Grill, M. Handloser, D. D. Medina, M. Dogru, F. Löbermann, D. Trauner, A. Hartschuh, T. Bein, J. Am. Chem. Soc. 2014, 136, 17802.

[144] B. Sun, C.-H. Zhu, Y. Liu, C. Wang, L.-J. Wan, D. Wang, Chem. Mater. 2017, 29, 4367.

[145] A. P. Côté, A. I. Benin, N. W. Ockwig, M. O'Keeffe, A. J. Matzger, O. M. Yaghi, Science 2005, 310, 1166.

[146] E. L. Spitler, J. W. Colson, F. J. Uribe-Romo, A. R. Woll, M. R. Giovino, A. Saldivar, W. R. Dichtel, Angew. Chem., Int. Ed. 2012, 51, 2623.

[147] J. W. Colson, J. A. Mann, C. R. DeBlase, W. R. Dichtel, J. Polym. Sci., Part A: Polym. Chem. 2015, 53, 378.

[148] D. D. Medina, M. L. Petrus, A. N. Jumabekov, J. T. Margraf, S. Weinberger, J. M. Rotter, T. Clark, T. Bein, ACS Nano 2017, 11, 2706.

[149] C. R. DeBlase, K. E. Silberstein, T.-T. Truong, H. D. Abruña, W. R. Dichtel, J. Am. Chem. Soc. 2013, 135, 16821.

[150] C. R. DeBlase, K. Hernández-Burgos, K. E. Silberstein, G. G. Rodríguez-Calero, R. P. Bisbey, H. D. Abruña, W. R. Dichtel, ACS Nano 2015, 9, 3178.

[151] X. Gou, Q. Zhang, Y. Wu, Y. Zhao, X. Shi, X. Fan, L. Huang, G. Lu, RSC Adv. 2016, 6, 39198.

[152] S.-L. Cai, Y.-B. Zhang, A. B. Pun, B. He, J. Yang, F. M. Toma, I. D. Sharp, O. M. Yaghi, J. Fan, S.-R. Zheng, W.-G. Zhang, Y. Liu, Chem. Sci. 2014, 5, 4693.

[153] D. Bessinger, L. Ascherl, F. Auras, T. Bein, J. Am. Chem. Soc. 2017, 139, 12035.

[154] T. Sick, A. G. Hufnagel, J. Kampmann, I. Kondofersky, M. Calik, J. M. Rotter, A. Evans, M. Döblinger, S. Herbert, K. Peters, D. Böhm, P. Knochel, D. D. Medina, D. Fattakhova-Rohlfing, T. Bein, J. Am. Chem. Soc. 2018, 140, 2085.

[155] S. Lin, C. S. Diercks, Y.-B. Zhang, N. Kornienko, E. M. Nichols, Y. Zhao, A. R. Paris, D. Kim, P. Yang, O. M. Yaghi, C. J. Chang, Science 2015, 349, 1208.

[156] C. S. Diercks, S. Lin, N. Kornienko, E. A. Kapustin, E. M. Nichols, C. Zhu, Y. Zhao, C. J. Chang, O. M. Yaghi, J. Am. Chem. Soc. 2018, 140, 1116.

[157] Y. Zhao, L. Guo, F. Gándara, Y. Ma, Z. Liu, C. Zhu, H. Lyu, C. A. Trickett, E. A. Kapustin, O. Terasaki, O. M. Yaghi, J. Am. Chem. Soc. 2017, 139, 13166.

[158] D. D. Medina, J. M. Rotter, Y. Hu, M. Dogru, V. Werner, F. Auras, J. T. Markiewicz, P. Knochel, T. Bein, J. Am. Chem. Soc. 2015, 137, 1016.

[159] R. P. Bisbey, C. R. DeBlase, B. J. Smith, W. R. Dichtel, J. Am. Chem. Soc. 2016, 138, 11433.

[160] J. I. Feldblyum, C. H. McCreery, S. C. Andrews, T. Kurosawa, E. J. G. Santos, V. Duong, L. Fang, A. L. Ayzner, Z. Bao, Chem. Commun. 2015, 51, 13894.

[161] S. Kandambeth, B. P. Biswal, H. D. Chaudhari, K. C. Rout, S. Kunjattu H, S. Mitra, S. Karak, A. Das, R. Mukherjee, U. K. Kharul, R. Banerjee, Adv. Mater. 2017, 29, 1603945. 
[162] M. A. Khayum, S. Kandambeth, S. Mitra, S. B. Nair, A. Das, S. S. Nagane, R. Mukherjee, R. Banerjee, Angew. Chem., Int. Ed. 2016, 55, 15604.

[163] M. Matsumoto, L. Valentino, G. M. Stiehl, H. B. Balch, A. R. Corcos, F. Wang, D. C. Ralph, B. J. Mariñas, W. R. Dichtel, Chem 2017, 4, 308.

[164] X. Feng, L. Chen, Y. Honsho, O. Saengsawang, L. Liu, L. Wang, A. Saeki, S. Irle, S. Seki, Y. Dong, D. Jiang, Adv. Mater. 2012, 24, 3026.

[165] X. Feng, L. Liu, Y. Honsho, A. Saeki, S. Seki, S. Irle, Y. Dong, A. Nagai, D. Jiang, Angew. Chem., Int. Ed. 2012, 51, 2618.

[166] S. Dalapati, M. Addicoat, S. Jin, T. Sakurai, J. Gao, H. Xu, S. Irle, S. Seki, D. Jiang, Nat. Commun. 2015, 6, 7786.

[167] J. Guo, Y. Xu, S. Jin, L. Chen, T. Kaji, Y. Honsho, M. A. Addicoat, J. Kim, A. Saeki, H. Ihee, S. Seki, S. Irle, M. Hiramoto, J. Gao, D. Jiang, Nat. Commun. 2013, 4, 2736.

[168] B. J. Smith, L. R. Parent, A. C. Overholts, P. A. Beaucage, R. P. Bisbey, A. D. Chavez, N. Hwang, C. Park, A. M. Evans, N. C. Gianneschi, W. R. Dichtel, ACS Cent. Sci. 2017, 3, 58.

[169] L. Hu, D. S. Hecht, G. Grüner, Chem. Rev. 2010, 110, 5790.

[170] P. Feng, W. Xu, Y. Yang, X. Wan, Y. Shi, Q. Wan, J. Zhao, Z. Cui, Adv. Funct. Mater. 2017, 27, 1604447.

[171] D. M. Sun, C. Liu, W. C. Ren, H. M. Cheng, Small 2013, 9, 1188.

[172] A. D. Franklin, Science 2015, 349, aab2750.

[173] H. Chen, S. Zeng, M. Chen, Y. Zhang, Q. Li, Carbon 2015, 92, 271.

[174] L. Yu, C. Shearer, J. Shapter, Chem. Rev. 2016, 116, 13413.

[175] D. S. Hecht, L. Hu, G. Irvin, Adv. Mater. 2011, 23, 1482.

[176] J. Lee, J. Kim, T. Hyeon, Adv. Mater. 2006, 18, 2073.

[177] M. Oschatz, P. Pré, S. Dörfler, W. Nickel, P. Beaunier, J.-N. Rouzaud, C. Fischer, E. Brunner, S. Kaskel, Carbon 2016, 105, 314.

[178] D. S. Su, S. Perathoner, G. Centi, Chem. Rev. 2013, 113, 5782.

[179] L. Borchardt, M. Oschatz, S. Kaskel, Chem. - Eur. J. 2016, 22, 7324.

[180] M. Oschatz, L. Borchardt, M. Thommes, K. A. Cychosz, I. Senkovska, N. Klein, R. Frind, M. Leistner, V. Presser, Y. Gogotsi, S. Kaskel, Angew. Chem., Int. Ed. 2012, 51, 7577.

[181] Y. Tao, M. Endo, M. Inagaki, K. Kaneko, J. Mater. Chem. 2011, $21,313$.

[182] H. Wang, S. Min, C. Ma, Z. Liu, W. Zhang, Q. Wang, D. Li, Y. Li, S. Turner, Y. Han, H. Zhu, E. Abou-Hamad, M. N. Hedhili, J. Pan, W. Yu, K. W. Huang, L. J. Li, J. Yuan, M. Antonietti, T. Wu, Nat. Commun. 2017, 8, 13592.

[183] H. B. Wu, X. W. Lue, Sci. Adv. 2017, 3, eaap9252.

[184] H. Nishihara, T. Hirota, K. Matsuura, M. Ohwada, N. Hoshino, T. Akutagawa, T. Higuchi, H. Jinnai, Y. Koseki, H. Kasai, Y. Matsuo, J. Maruyama, Y. Hayasaka, H. Konaka, Y. Yamada, S. Yamaguchi, K. Kamiya, T. Kamimura, H.i Nobukuni, F. Tani, Nat. Commun. 2017, 8, 109.

[185] M. Oschatz, W. Nickel, M. Thommes, K. A. Cychosz, M. Leistner, M. Adam, G. Mondin, P. Strubel, L. Borchardt, S. Kaskel, J. Mater. Chem. A 2014, 2, 18472.

[186] V. Presser, M. Heon, Y. Gogotsi, Adv. Funct. Mater. 2011, 21, 810.

[187] J. Chmiola, C. Largeot, P.-L. Taberna, P. Simon, Y. Gogotsi, Science 2010, 328, 480.

[188] M. Heon, S. Lofland, J. Applegate, R. Nolte, E. Cortes, J. D. Hettinger, P.-L. Taberna, P. Simon, P. Huang, M. Brunet, Y. Gogotsi, Energy Environ. Sci. 2011, 4, 135.

[189] Z. G. Cambaz, G. N. Yushin, Y. Gogotsi, K. L. Vyshnyakova, L. N. Pereselentseva, J. Am. Ceram. Soc. 2006, 89, 509.

[190] M. Zeiger, T. Ariyanto, B. Krüner, N. J. Peter, S. Fleischmann, B. J. M. Etzold, V. Presser, J. Mater. Chem. A 2016, 4, 18899.

[191] T. Ariyanto, G.-R. Zhang, F. Riyahi, J. Gläsel, B. J. M. Etzold, Carbon 2017, 115, 422.

[192] a) Z. Ma, T. Kyotani, A. Tomita, Chem. Comm. 2000, 2365; b) H. Nishihara, T. Kyotani, Chem. Commun. 2018, 54, 5648.
[193] Y. Xia, R. Mokaya, G. S. Walker, Y. Zhu, Adv. Energy Mater. 2011, 1, 678.

[194] Y. Korenblit, A. Kajdos, W. C. West, M. C. Smart, E. J. Brandon, A. Kvit, J. Jagiello, G. Yushin, Adv. Funct. Mater. 2012, 22, 1655.

[195] A. Berenguer-Murcia, R. R. Ruiz-Rosas, J. Garcia-Aguilar, K. Nueangnoraj, H. Nishihara, E. Morallon, T. Kyotani, D. CazorlaAmoros, Phys. Chem. Chem. Phys. 2013, 15, 10331.

[196] J. M. Rosas, R. Ruiz-Rosas, R. Berenguer, D. Cazorla-Amorós, E. Morallón, H. Nishihara, T. Kyotani, J. Rodríguez-Mirasol, T. Cordero, J. Mater. Chem. A 2016, 4, 4610.

[197] G.-P. Hao, Q. Zhang, M. Sin, F. Hippauf, L. Borchardt, E. Brunner, S. Kaskel, Chem. Mater. 2016, 28, 8715.

[198] M. Oschatz, E. Kockrick, M. Rose, L. Borchardt, N. Klein, I. Senkovska, T. Freudenberg, Y. Korenblit, G. Yushin, S. Kaskel, Carbon 2010, 48, 3987.

[199] L. Borchardt, M. Oschatz, S. Kaskel, Mater. Horiz. 2014, 1, 157.

[200] A. H. Lu, F. Schüth, Adv. Mater. 2006, 18, 1793.

[201] S. Leyva-García, D. Lozano-Castelló, E. Morallón, D. Cazorla-Amorós, J. Mater. Chem. A 2016, 4, 4570.

[202] M.-L. Lin, C.-C. Huang, M.-Y. Lo, C.-Y. Mou, J. Phys. Chem. C 2008, $112,867$.

[203] C.-Y. Liu, C.-F. Chen, J.-P. Leu, C.-C. Lu, K.-H. Liao, Sens. Actuators, B 2009, 143, 12 .

[204] H. Nishihara, T. Kwon, Y. Fukura, W. Nakayama, Y. Hoshikawa, S. Iwamura, N. Nishiyama, T. Itoh, T. Kyotani, Chem. Mater. 2011, 23,3144

[205] T. Kwon, H. Nishihara, Y. Fukura, K. Inde, N. Setoyama, Y. Fukushima, T. Kyotani, Microporous Mesoporous Mater. 2010, 132,421

[206] J. Zhi, Y. Wang, S. Deng, A. Hu, RSC Adv. 2014, 4, 40296.

[207] H. Nishihara, T. Kyotani, Adv. Mater. 2012, 24, 4473.

[208] T. Kyotani, L. Tsai, A. Tomita, Chem. Mater. 1996, 8, 2109.

[209] K. Jian, H.-S. Shim, A. Schwartzman, G. P. Crawford, R. H. Hurt, Adv. Mater. 2003, 15, 164

[210] Q. Yang, W. Xu, A. Tomita, T. Kyotani, J. Am. Chem. Soc. 2005, 127, 8956.

[211] H. Orikasa, T. Akahane, M. Okada, Y. Tong, J.-i. Ozaki, T. Kyotani, J. Mater. Chem. 2009, 19, 4615.

[212] A. L. Mohana Reddy, M. M. Shaijumon, S. R. Gowda, P. M. Ajayan, Nano Lett. 2009, 9, 1002.

[213] C. Liang, K. Hong, G. A. Guiochon, J. W. Mays, S. Dai, Angew. Chem., Int. Ed. 2004, 43, 5785.

[214] S. Tanaka, N. Nishiyama, Y. Egashira, K. Ueyama, Chem. Commun. 2005, 2125.

[215] Y. Meng, D. Gu, F. Zhang, Y. Shi, H. Yang, Z. Li, C. Yu, B. Tu, D. Zhao, Angew. Chem., Int. Ed. 2005, 44, 7053.

[216] L. Chuenchom, R. Kraehnert, B. M. Smarsly, Soft Matter 2012, 8, 10801.

[217] T. Y. Ma, L. Liu, Z. Y. Yuan, Chem. Soc. Rev. 2013, 42, 3977.

[218] D. Feng, Y. Lv, Z. Wu, Y. Dou, L. Han, Z. Sun, Y. Xia, G. Zheng, D. Zhao, J. Am. Chem. Soc. 2011, 133, 15148.

[219] M. Si, D. Feng, L. Qiu, D. Jia, A. A. Elzatahry, G. Zheng, D. Zhao, J. Mater. Chem. A 2013, 1, 13490.

[220] G. Deng, Y. Zhang, C. Ye, Z. Qiang, G. E. Stein, K. A. Cavicchi, B. D. Vogt, Chem. Commun. 2014, 50, 12684.

[221] K. Lee, H. Song, K. H. Lee, S. H. Choi, J. H. Jang, K. Char, J. G. Son, ACS Appl. Mater. Interfaces 2016, 8, 22516.

[222] L. Borchardt, M. Oschatz, M. Lohe, V. Presser, Y. Gogotsi, S. Kaskel, Carbon 2012, 50, 3987.

[223] Z. Wu, P. A. Webley, D. Zhao, Langmuir 2010, 26, 10277.

[224] A. Labiano, M. Dai, D. Taylor, W.-S. Young, T. H. Epps, K. Rege, B. D. Vogt, Microporous Mesoporous Mater. 2012, 160, 143.

[225] M. Dai, L. Song, J. T. LaBelle, B. D. Vogt, Chem. Mater. 2011, 23, 2869.

[226] Z. Sun, B. Sun, M. Qiao, J. Wei, Q. Yue, C. Wang, Y. Deng, S. Kaliaguine, D. Zhao, J. Am. Chem. Soc. 2012, 134, 17653. 